\title{
Mechanisms of salt tolerance in habanero pepper plants (Capsicum chinense Jacq.): Proline accumulation, ions dynamics and sodium root-shoot partition and compartmentation
}

\section{Emanuel Bojórquez-Quintal ${ }^{1}$, Ana Velarde-Buendía ${ }^{2}$, Ángela Ku-González ${ }^{1}$, Mildred Carillo-Pech ${ }^{1}$, Daniela Ortega-Camacho ${ }^{3}$, Ileana Echevarría-Machado ${ }^{1}$, Igor Pottosin ${ }^{2}$ and Manuel Martínez-Estévez ${ }^{1 *}$}

${ }^{1}$ Unidad de Bioquímica y Biología Molecular de Plantas, Centro de Investigación Científica de Yucatán, Yucatán, México

${ }^{2}$ Centro Universitario de Investigaciones Biomédicas, Universidad de Colima, Colima, México

${ }^{3}$ Unidad de Ciencias del Agua, Centro de Investigación Científica de Yucatán, Yucatán, México

Edited by:

Vadim Volkov, London Metropolitan University, UK

Reviewed by:

Sergey Shabala, University of

Tasmania, Australia

Vadim Volkov, London Metropolitan

University, UK

Soledad Francisca Undurraga,

Universidad Mayor, Chile

*Correspondence:

Manuel Martínez-Estévez, Unidad

de Bioquímica y Biología Molecular de Plantas, Centro de Investigación Científica de Yucatán (CICY), Calle 30 \# 130, Col. Chuburná de Hidalgo, Mérida 97200, México

e-mail: /uismanh@cicy.mx
Despite its economic relevance, little is known about salt tolerance mechanisms in pepper plants. To address this question, we compared differences in responses to $\mathrm{NaCl}$ in two Capsicum chinense varieties: Rex (tolerant) and Chichen-Itza (sensitive). Under salt stress $(150 \mathrm{mM} \mathrm{NaCl}$ over 7 days) roots of Rex variety accumulated 50 times more compatible solutes such as proline compared to Chichen-Itza. Mineral analysis indicated that $\mathrm{Na}^{+}$is restricted to roots by preventing its transport to leaves. Fluorescence analysis suggested an efficient $\mathrm{Na}^{+}$compartmentalization in vacuole-like structures and in small intracellular compartments in roots of Rex variety. At the same time, $\mathrm{Na}^{+}$in Chichen-Itza plants was compartmentalized in the apoplast, suggesting substantial $\mathrm{Na}^{+}$extrusion. Rex variety was found to retain more $\mathrm{K}^{+}$in its roots under salt stress according to a mineral analysis and microelectrode ion flux estimation (MIFE). Vanadate-sensitive $\mathrm{H}^{+}$efflux was higher in Chichen-Itza variety plants, suggesting a higher activity of the plasma membrane $\mathrm{H}^{+}$-ATPase, which fuels the extrusion of $\mathrm{Na}^{+}$, and, possibly, also the re-uptake of $\mathrm{K}^{+}$. Our results suggest a combination of stress tolerance mechanisms, in order to alleviate the salt-induced injury. Furthermore, $\mathrm{Na}^{+}$extrusion to apoplast does not appear to be an efficient strategy for salt tolerance in pepper plants.

Keywords: salt tolerance, pepper, roots, proline accumulation, sodium compartmentalization, potassium retention, ion fluxes, $\mathrm{H}^{+}$-ATPase

\section{INTRODUCTION}

The excess of soluble salts in soil, particularly $\mathrm{NaCl}$, causes three types of stresses in plants: osmotic, ionic, and oxidative. These stresses reduce absorption and induce a massive efflux of water and ions $\left(\mathrm{K}^{+}\right)$in plant cells, resulting in water, and nutritional imbalances. The accumulation of $\mathrm{Na}^{+}$to toxic concentrations and the production of reactive oxygen species (ROS) reduce the growth, yield, and production of economically important crops, such as cereals and vegetables (Munns and Tester, 2008; Bojórquez-Quintal et al., 2012). Plants in relation to salt can be classified into two groups: halophytes (growth stimulated at moderate and tolerant to high salinity) and glycophytes, which display a suppressed growth in a saline environment (Flowers and Colmer, 2008; Ruan et al., 2010). In halophytes, various adaptive mechanisms to tolerate high levels of salt have been identified and intensively studied (Ruan et al., 2010; Adolf et al., 2013; Shabala, 2013). Unfortunately, some of these mechanisms may not be directly transferred to crop plants, which are mostly glycophytes (Zhang and Shi, 2013). Yet, several crops are relatively salt resistant, and there are also substantial differences in the salt tolerance between nearly isogenic varieties within the same plant species. Salt tolerance is a complex trait controlled by many genes and involves various biochemical and physiological mechanisms. The fine tuning of these mechanisms is necessary to achieve a significant increase in tolerance to salt (Zhang and Shi, 2013; Adem et al., 2014).

Proline is the most common compatible osmolyte in plants and has therefore been extensively studied. The accumulation of this amino acid is an important regulatory mechanism under osmotic stress (Huang et al., 2013). Proline is a multifunctional amino acid (Szabados and Savouré, 2009). In many plant species, the accumulation of proline has been associated with tolerance to salt stress and has even been used as a marker to select tolerant genotypes (Ashraf and Harris, 2004). However, a negative correlation between the accumulation of proline and salt tolerance has also been reported, indicating discrepancies in its function (Lutts et al., 1999; Chen et al., 2007a). Proline accumulation is made possible by the increase in the expression and activity of the synthesis enzymes ( $\Delta$-pyrroline-5-carboxylate synthetase, P5CS; $\Delta$-pyrroline-5-carboxylate reductase, P5CR) or 
by the decrease in the degradation enzymes, proline dehydrogenase or proline oxidase (PDH or POX), and P5C dehydrogenase (P5CDH) (Huang et al., 2013). Under salt stress, the P5CS1 and $P D H$ genes are positively and negatively regulated, respectively (Kishor et al., 2005; Verslues and Sharma, 2010; Jaarsma et al., 2013). Similarly, the overexpression of the P5CS gene increases proline synthesis under salt stress and improves tolerance to salt (Kishore et al., 1995; Hmida-Sayari et al., 2005).

The roots are the first site of contact with high concentrations of $\mathrm{Na}^{+}$in the soil and therefore of the uptake or absorption of salt. $\mathrm{Na}^{+}$influx is mediated by non-selective cation channels (NSCC), high-affinity $\mathrm{K}^{+}$transporters (HKTs), and low-affinity cation transporters (LCT) in the root epidermal cells (Apse and Blumwald, 2007; Plett and Moller, 2010; Maathuis, 2014). $\mathrm{Na}^{+}$is then transported radially toward the root xylem via the apoplast and symplast. After being loaded into the xylem, $\mathrm{Na}^{+}$is finally transported to the shoots by xylem flow (Adams and Shin, 2014). In contrast to halophytes, $\mathrm{Na}^{+}$is not an essential element for most plants and becomes highly toxic at high concentrations, particularly in the aerial parts of the plant. Therefore, it is necessary to maintain efficient control of $\mathrm{Na}^{+}$content and intracellular compartmentalization in plant tissues. The high-affinity potassium transporters (HKTs), the $\mathrm{Na}^{+} / \mathrm{H}^{+}$SOS1 (salt overly sensitive) antiporters on the plasma membrane and the intracellular NHX antiporters $\left(\mathrm{Na}^{+} / \mathrm{H}^{+}\right)$are transporters involved in the $\mathrm{Na}^{+}$ homeostasis (Almeida et al., 2013; Adams and Shin, 2014).

The regulation of $\mathrm{K}^{+}$homeostasis is essential for plant adaptation to biotic and abiotic stresses. This adaptation is associated with the wide range of functions in which $\mathrm{K}^{+}$participates (Anschütz et al., 2014; Demidchik, 2014; Shabala and Pottosin, 2014). Recently, $\mathrm{K}^{+}$retention in the cells of roots and leaves has been identified as an important trait for salt tolerance. A strong negative correlation between the magnitude of salt-induced $\mathrm{K}^{+}$ loss and salt tolerance, observed in various crop species, suggested $\mathrm{K}^{+}$retention as a selection criterion between salt tolerant and sensitive varieties (Chen et al., 2005, 2007b,c; Smethurst et al., 2008; Lu et al., 2013; Wu et al., 2013; Bonales-Alatorre et al., 2013a). Furthermore, it has been observed that the exogenous administration of organic compounds and divalent cations prevents $\mathrm{K}^{+}$ efflux (Cuin and Shabala, 2005, 2007a,b; Shabala et al., 2006; Zhao et al., 2007; Chen et al., 2007a; Zepeda-Jazo et al., 2008). Efficient control of membrane potential due to the $\mathrm{H}^{+}$-ATPase activity was shown to be important for the salt tolerance in several species (Chen et al., 2007b; Cuin et al., 2008; Hariadi et al., 2011; Bose et al., 2013, 2014). A more negative membrane potential during salt stress reduces the driving force for the $\mathrm{K}^{+}$loss and facilitates the $\mathrm{K}^{+}$absorption, thus allowing plants to retain $\mathrm{K}^{+}$ in the cytosol (Chen et al., 2007b; Bose et al., 2013). Likewise, the $\mathrm{H}^{+}$-ATPase activity is essential to fuel $\mathrm{Na}^{+} / \mathrm{H}^{+}$exchangers in the plasma membrane (SOS1). At the same time, a higher activity of the $\mathrm{H}^{+}$pump consumes a large amount of ATP, hence has a higher energetic cost (Malagoli et al., 2008). Thus, keeping electrochemical gradients for physiologically important cations across the plasma membrane could present an energetic burden, so this tolerance mechanism cannot be considered permanent and may be used as a temporary solution at early times after the onset of the salt stress (Bose et al., 2013, 2014).
Peppers (Capsicum spp.) are an economically important genus of the Solanaceae family, which also includes tomatoes and potatoes. Among the 32 species native to America, C. annuum L., C. baccatum L., C. frutescens L., C. pubescens L., and C. chinense Jacq. are cultivated (Moscone et al., 2007; Perry et al., 2007). Overall, pepper plants are grown around the world because of their adaptation to different agro-climatic regions and their wide variety of shapes, sizes, colors, and pungencies of the fruit (Qin et al., 2014). However, these plants are sensitive to various biotic stresses, such as viruses and Oomycetes and abiotic factors such as drought and salinity. In fact, pepper plants are considered moderately sensitive, sensitive or highly susceptible to salt stress (Maas and Hoffman, 1977; Aktas et al., 2006). Nevertheless, despite their economic importance as a horticultural species, very little is known about the mechanisms of tolerance to high salt concentrations. To contribute to the understanding of salt stress in species of economic importance such as peppers, the difference in salt sensitivity of two varieties of the species $C$. chinense Jacq, commonly known as habanero pepper, was evaluated in this study. Furthermore, possible mechanisms of salt stress tolerance for the two varieties were addressed by electrophysiological studies using selective microelectrodes (MIFE) and by subcellular localization of $\mathrm{Na}^{+}$using fluorescent indicators.

\section{MATERIALS AND METHODS PLANT MATERIAL AND GROWTH CONDITIONS}

Habanero pepper (C. chinense Jacq.) seeds of the Chichen-Itza (Seminis ${ }^{\circledR}$ ) and Rex (Mayan Chan obtained in CICY) varieties were used in this study. To disinfect the seeds, they were rinsed in $80 \%$ ethanol $(\mathrm{v} / \mathrm{v})$ for $5 \mathrm{~min}$ and washed continuously with sterile water. Seeds were then incubated with $30 \%(\mathrm{v} / \mathrm{v})$ sodium hypochlorite (Cloralex 5\% NaOCl) and Tween (1 drop) for $15 \mathrm{~min}$. Washes were continuous, and the seeds were kept in sterile water for $48 \mathrm{~h}$ at $4^{\circ} \mathrm{C}$ in the dark. After stratification, seeds of both varieties were incubated (in the dark) in Petri dishes with filter paper moistened with sterile water until the emergence of the radicle.

For the hydroponic experiments, germinated seeds were transferred to plastic containers with vermiculite moistened with a Hoagland solution to a fifth of its ionic strength (H1/5). Seeds were incubated under photoperiods of $16 / 8 \mathrm{~h} \mathrm{light/dark}$ at $25^{\circ} \mathrm{C}$. The light intensity was $123 \mu \mathrm{mol} \mathrm{m} \mathrm{m}^{-2} \mathrm{~s}^{-1}$. Seedlings were irrigated for 45 days with a sterile water solution and $\mathrm{H} 1 / 5$ with 7 -day intervals. The modified Hoagland solution at one-fifth of its ionic strength ( $\mathrm{H} 1 / 5)$ contained the following: $1.2 \mathrm{mM} \mathrm{KNO}_{3}, 0.8 \mathrm{mM}$ $\mathrm{Ca}\left(\mathrm{NO}_{3}\right)_{2}, 0.2 \mathrm{mM} \mathrm{KH} \mathrm{PO}_{4}, 0.2 \mathrm{mM} \mathrm{MgSO}_{4}, 50 \mu \mathrm{M} \mathrm{CaCl}$, $12.5 \mu \mathrm{M} \mathrm{H}_{3} \mathrm{BO}_{3}, 1 \mu \mathrm{M} \mathrm{MnSO}, 1 \mu \mathrm{M} \mathrm{ZnSO}, 0.5 \mu \mathrm{M} \mathrm{CuSO}_{4}$, $0.1 \mu \mathrm{M}\left(\mathrm{NH}_{4}\right)_{6} \mathrm{Mo}_{7} \mathrm{O}_{24}, 0.1 \mu \mathrm{M} \mathrm{NaCl}$, and $10 \mu \mathrm{M}$ Fe-EDTA, $\mathrm{pH} 6.8$.

For electrophysiological experiments and subcellular $\mathrm{Na}^{+}$ localization, seeds with radicles were transferred to Petri dishes containing modified Gamborg-B5 growth medium (Sales B5, Sigma) at half ionic strength (B5/2). B5/2 medium was supplemented with $0.5 \%$ sucrose $(\mathrm{w} / \mathrm{v})$ and $1 \%$ agar $(\mathrm{w} / \mathrm{v})$. The $\mathrm{pH}$ was adjusted to 5.8. Seedlings 10 days of age with a primary root $8-10 \mathrm{~cm}$ in length were used for this experiment. 


\section{NaCI STRESS TREATMENT}

Forty-five- to fifty-day-old seedlings (growing in vermiculite) of Rex and Chichen-Itza varieties were used. After pre-treatment with a solution of $\mathrm{H} 1 / 5$ for 7 days to avoid mechanical damage, seedlings homogeneous in size were selected. Three replicates of 10 seedlings of each variety were subjected to 7 days of treatment at concentrations of $0,50,100$, and $150 \mathrm{mM} \mathrm{NaCl}$ in $\mathrm{H} 1 / 5$ solution. Treatments were performed in a culture room with photoperiods of $16 / 8 \mathrm{~h}$ light/dark at $25^{\circ} \mathrm{C}$. At the end of the experiment, the seedlings were harvested and washed with sterile water to remove excess $\mathrm{NaCl}$, and the fresh weight (FW), dry weight (DW), and the water content was determined by the formula (FW-DW)/FW. Each type of sample was dried in an electric oven at $60^{\circ} \mathrm{C}$ for $72 \mathrm{~h}$. The leaves and roots were used for the determination of proline, $\mathrm{Na}^{+}$, and $\mathrm{K}^{+}$content.

\section{PROLINE CONTENT}

A modification of the method described by Bates et al. (1973) was used to determine proline content. Briefly, dry leaf and root tissues were macerated and homogenized in $10 \mathrm{~mL}$ of boiling water. For each reaction, $2 \mathrm{~mL}$ of the supernatant was mixed with $2 \mathrm{~mL}$ of acetic acid and $2 \mathrm{~mL}$ of ninhydrin. The reaction mixture was heated in a water bath at $100^{\circ} \mathrm{C}$ for $60 \mathrm{~min}$, and the reaction was stopped in an ice bath. For extraction, $4 \mathrm{~mL}$ of toluene was added, and samples were mixed vigorously for 15-20 s. Samples were then set aside to allow separation of the organic and aqueous phases. The organic phase containing the chromophore was collected in a new tube, and absorbance was read at $520 \mathrm{~nm}$ using toluene as a blank. Proline concentration was determined from a standard curve, and concentrations were calculated based on DW.

\section{SODIUM AND POTASSIUM QUANTIFICATION}

Samples of dried leaves and roots were weighed, and $\mathrm{HNO}_{3}: \mathrm{H}_{2} \mathrm{O}_{2}$ was added at a 5:1 (v:v) ratio. Microwave digestion was performed at $1200 \mathrm{~W}$ using a ramp of $15 \mathrm{~min}$ to $200^{\circ} \mathrm{C}, 10 \mathrm{~min}$ to $200^{\circ} \mathrm{C}$, and $5 \mathrm{~min}$ to $170^{\circ} \mathrm{C}$. Subsequently, samples were adjusted to a volume of $25 \mathrm{~mL}$ with water (Milli Q), and $\mathrm{Na}^{+}$and $\mathrm{K}^{+}$content was quantified by inductively coupled plasma atomic emission spectroscopy (ICP-AES, Thermo IRIS Intrepid II XDL, New York, USA). Standard curves were used for each element.

\section{MIFE TECHNIQUE}

The net flux of $\mathrm{K}^{+}$and $\mathrm{H}^{+}$on the surface of the roots of the two varieties of $C$. chinense was measured non-invasively by the microelectrode ion flux estimation (MIFE) technique (Newman, 2001). For MIFE studies, seedlings grown in vitro with roots of $8-$ $10 \mathrm{~cm}$ in length were transferred and fixed horizontally to a measuring chamber. Subsequently, $25 \mathrm{~mL}$ of measurement solutions were added for $\mathrm{K}^{+}(0.5 \mathrm{mM} \mathrm{KCl}, 0.1 \mathrm{mM} \mathrm{CaCl} 2,5 \mathrm{mM} \mathrm{MES}$, $2 \mathrm{mM}$ Tris base, $\mathrm{pH} 6.0)$ and for $\mathrm{H}^{+}(0.5 \mathrm{mM} \mathrm{KCl}$ and $0.1 \mathrm{mM}$ $\mathrm{CaCl}_{2}$, without $\mathrm{pH}$-buffer) and incubated for $1 \mathrm{~h}$ to allow stabilization. Two electrodes selective for $\mathrm{K}^{+}$and $\mathrm{H}^{+}$were used in each experiment. For salt stress treatment, $\mathrm{NaCl}$ solution was added to the measuring chamber to a final concentration of $150 \mathrm{mM}$. Before the experiment, the microelectrodes were filled with $0.5 \mathrm{mM} \mathrm{KCl}$ for $\mathrm{K}^{+}$or $0.15 \mathrm{mM} \mathrm{NaCl}$ and $0.04 \mathrm{mM} \mathrm{KH}_{2} \mathrm{PO}_{4}$ for $\mathrm{H}^{+}$, and the tip of each electrode was filled with the ion-selective resin (ion-liquid exchanger, LIX Fluka, Sigma-Aldrich) for the ion measured. Two electrodes were then mounted in a micromanipulator, and located perpendicular to the root axis $20-40 \mu \mathrm{m}$ from the mature root zone, $1-2 \mathrm{~cm}$ from the root apex. Measurements were initiated by moving the electrodes $50 \mu \mathrm{m}$ back and then forth and back in a cyclic manner every $8 \mathrm{~s}$. The software CHART recorded potential differences between the two measurement positions and converted them into electrochemical potential differences using the Nernst slope. Net ion fluxes were calculated using the MIFEFLUX software for cylindrical diffusion geometry.

\section{LOCALIZATION AND SUBCELLULAR ACCUMULATION OF SODIUM}

Sodium Green ${ }^{\mathrm{TM}}$ indicator (S-6901, Molecular Probes, Life Technologies) was used to evaluate the subcellular localization and accumulation of sodium in the roots of $C$. chinense. Seedlings grown in vitro were incubated in a measurement solution $(0.5 \mathrm{mM} \mathrm{KCl}, 0.1 \mathrm{mM} \mathrm{CaCl}, 5 \mathrm{mM}$ MES, $2 \mathrm{mM}$ Tris base, $\mathrm{pH}$ 6.0) supplemented or not with $150 \mathrm{mM} \mathrm{NaCl}$. After 60 min of treatment, control, and $\mathrm{NaCl}$ treated seedlings were washed with distilled water and a solution of $0.5 \mathrm{mM} \mathrm{CaCl}$. Root segments $(1-1.5 \mathrm{~cm}$ long) were cut from the mature zone to $1-2 \mathrm{~cm}$ from the root apex and were incubated for $60 \mathrm{~min}$ in Eppendorf tubes of $500 \mu \mathrm{L}$ (measurement solution) with $10 \mu \mathrm{M}$ of Sodium Green ${ }^{\mathrm{TM}}$ (sodium staining) and $20 \mu \mathrm{M}$ of FM $^{\circledR} 4$-64 (membrane staining, T-13320, Molecular Probes, Life Technologies). Excess dye was removed, and the primary root segments were placed on a slide. Approximately $10 \mu \mathrm{L}$ of Vectashield (H-1000, Vector Laboratories, Inc.) with DAPI (nuclei staining, D3571, Molecular Probes, Life Technologies) was added. The fluorescence was observed using the confocal microscope FluoView $^{\mathrm{TM}}$ FV1000 (Olympus, Japan). A UPLFLN 40X0 (oil, NA: 1.3) lens was used with a scanning speed of $10 \mu \mathrm{s} /$ pixel. DAPI, Sodium Green ${ }^{\mathrm{TM}}$, and FM4-64 exhibit excitation and emission wavelengths of $358-461 \mathrm{~nm}, 507-532 \mathrm{~nm}$, and 515-670 nm, respectively. $Z$ images had a resolution of $512 \times 512$ pixels and were projected as a single image. Fluorophores were merged using the software FV10-ASW 3.01b.

\section{STATISTICAL ANALYSIS}

Data were analyzed using a One-Way analysis of variance (ANOVA) (Sigma Stat Version 3.1). Treatment averages were compared using Tukey's range test.

\section{RESULTS}

\section{VARIETIES OF $\boldsymbol{C}$. CHINENSE DIFFER IN SENSITIVITY TO NaCI STRESS}

Different varieties of $C$. chinense such as Rex and Chichen-Itza differ in their morphologic characteristics (fruit color, size, and root system architecture), as shown in Figures 1A,C. These two varieties exhibit differing sensitivities to salt stress, Rex being more tolerant than Chichen-Itza (Figures 1B,C). A concentration of $150 \mathrm{mM}$ of $\mathrm{NaCl}$ over 7 days of culture in hydroponic conditions had a strong impact on the growth of the two varieties. Loss of turgor, leaf abscission, and darkening of the root system were observed, especially in the variety Chichen-Itza (Figures 1B,C).

A significant reduction of fresh and DWs was also induced by $\mathrm{NaCl}$ in both genotypes (Figures 2A,B). Under salt stress, the FW reduction was greater in Chichen-Itza, (75\%) than in the Rex 
variety (50\%) (Figure 2A). The water content in the Rex variety was identical to the water content in control seedlings with no salt treatments. However, the water content in the ChichenItza variety was significantly lower than in the untreated controls (Figure 2C). It is noteworthy that although symptoms of stress (wilting and senescence) were observed at concentrations below $150 \mathrm{mM} \mathrm{NaCl}$, the effect on growth parameters was not significant between varieties by the end of the measurement period (data not shown). For this reason, a dose of $150 \mathrm{mM} \mathrm{NaCl}$ was selected for subsequent studies. This concentration has been used in various studies with glycophytes such as A. thaliana, S. tuberosum, and S. lycopersicum (Apse et al., 1999; RodríguezRosales et al., 2008; Jaarsma et al., 2013).
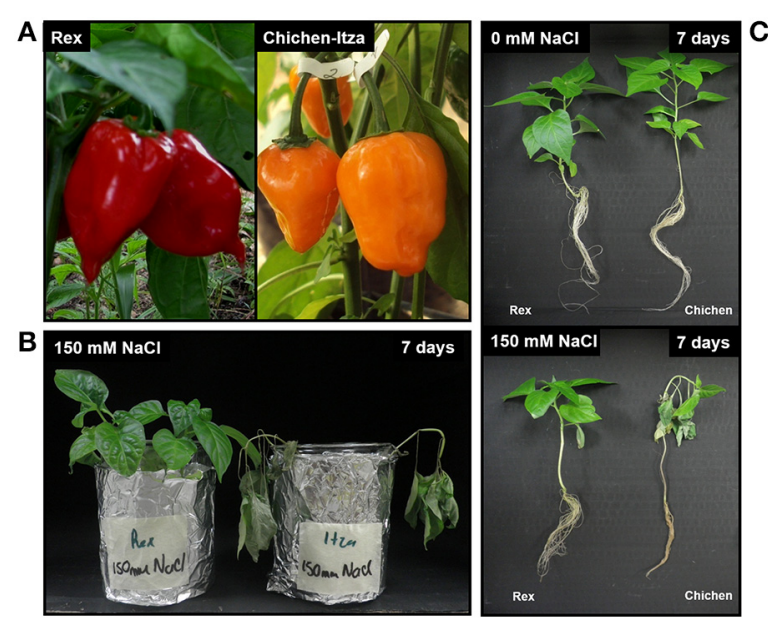

FIGURE 1 | Morphologic and sensitivity differences to $\mathrm{NaCl}$ stress in two varieties of $\boldsymbol{C}$. chinense. (A) Representative color of ripe habanero pepper fruits of the Rex (red) and Chichen-Itza (orange) varieties.

(B) Forty-five-day-old seedlings of two varieties of $C$. chinense after 7 days of culture in $\mathrm{H} 1 / 5$ solution supplemented with $150 \mathrm{mM} \mathrm{NaCl}$.

(C) Appearance and sensitivity of Rex and Chichen-Itza seedlings after 7 days of treatment under control conditions (top) and $150 \mathrm{mM} \mathrm{NaCl}$ (bottom).

\section{EFFECT OF NaCI ON PROLINE ACCUMULATION IN DIFFERENT VARIETIES OF C. CHINENSE}

Many species of plants accumulate compatible solutes, such as proline, in response to abiotic stresses such as drought and salinity. In the varieties of $C$. chinense studied, proline accumulation was analyzed in the leaves and roots of seedlings grown in hydroponic cultures and subjected to 0 (control) or $150 \mathrm{mM}$ $\mathrm{NaCl}$ for 7 days. Proline concentrations in the roots and leaves were similar in both varieties in the absence of salt. The proline concentration was higher in the leaves than in the roots (Figure 3). After 7 days of salt stress, the proline content in the Rex variety increased approximately 6.0-fold compared to control. However, in the Chichen-Itza variety, the values were similar to those in control seedlings growing without $\mathrm{NaCl}$ (Figure 3A). The same effect was observed in the roots as in the leaves. In the Rex variety, proline levels were 16-fold higher compared to control (Figure 3B). Surprisingly, the accumulation of proline in the roots was 50-fold higher in the Rex than in the Chichen-Itza variety after 7 days of treatment with $\mathrm{NaCl}$ (Figure 3B).

\section{POTASSIUM RETENTION AND SODIUM ACCUMULATION IN ROOTS UNDER SALT STRESS}

$\mathrm{K}^{+}$and $\mathrm{Na}^{+}$accumulation patterns in the two varieties of $C$. chinense are presented in Figure 4. In the absence of salt stress, $\mathrm{K}^{+}$content in the leaves and roots did not significantly differ between these varieties (Figures 4A,D). A higher $\mathrm{K}^{+}$concentration was observed in the leaves as compared to roots, due to the $\mathrm{K}^{+}$accumulation on the top of transpiration stream (Conn and Gilliham, 2010). $\mathrm{NaCl}$ stress did not modify $\mathrm{K}^{+}$content in the leaves in either variety of $C$. chinense (Figure 4A). However, a significant decrease in $\mathrm{K}^{+}$was observed in the roots of seedlings from the Chichen-Itza variety under salt stress. No significant reduction of root $\mathrm{K}^{+}$was observed in the Rex variety (Figure 4D). Furthermore, no differences in $\mathrm{K}^{+}$were observed for concentrations lower than $150 \mathrm{mM}$ of $\mathrm{NaCl}$ in either variety (Figure S1).
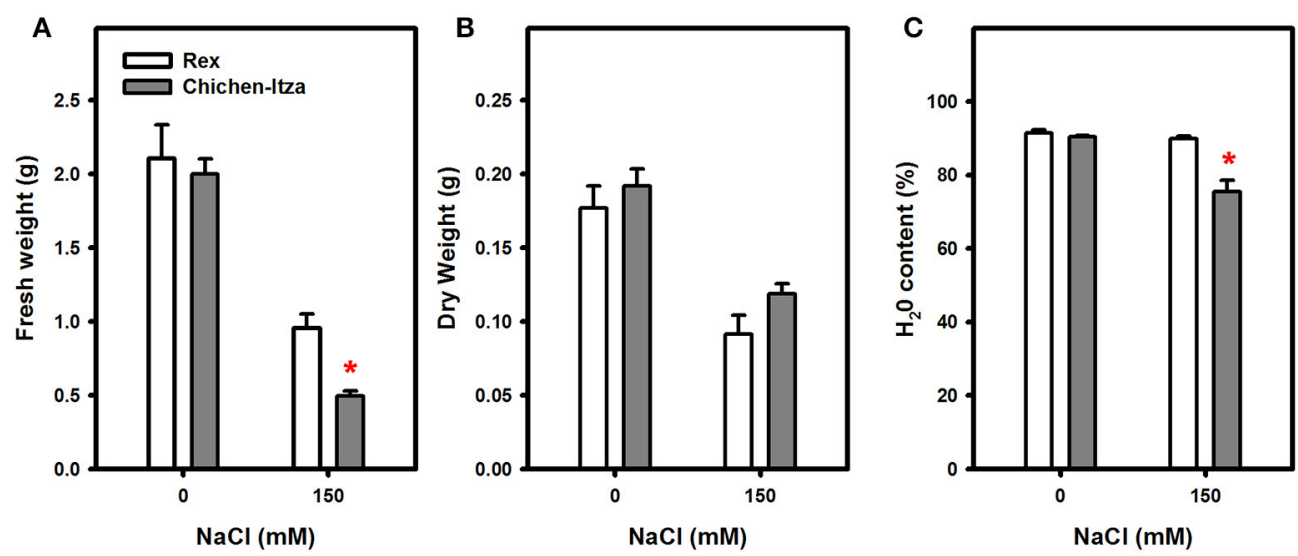

FIGURE 2 | Effect of saline stress $(150 \mathrm{mM} \mathrm{NaCl})$ on fresh weight (A), dry weight (B), and water content (C) of Chichen-Itza and Rex varieties seedlings after 7 days of culture with $150 \mathrm{mM}$ $\mathrm{NaCl}$. The white bars (Rex) and gray bars (Chichen-Itza) represent the mean FW, DW, and WC for the different treatments, ME \pm $\mathrm{SD}(n=6$ seedlings). The asterisk indicates statistically significant differences between varieties for each treatment $(P<0.050$, Tukey's test) 
In absence of salt stress, $\mathrm{Na}^{+}$content in the leaves and roots of both varieties was minimal, with values of $0.02 \mathrm{mmol}$ and $0.04 \mathrm{mmol} \mathrm{g} \mathrm{DW}^{-1}$, respectively. Treatment with $150 \mathrm{mM}$ $\mathrm{NaCl}$ increased the $\mathrm{Na}^{+}$content in the leaves; however, no differences were observed between the two varieties (Figure 4B). $\mathrm{Na}^{+}$content increased in the roots treated with salt in both varieties and was surprisingly higher in Rex (twofold) compared to Chichen-Itza variety (Figure 4E). The $\mathrm{Na}^{+} / \mathrm{K}^{+}$ratio in leaves and roots were very similar between pepper varieties when $\mathrm{NaCl}$ was not supplied (Figures 4C,F). As a consequence of increase in $\mathrm{Na}^{+}$ and decreases in $\mathrm{K}^{+}$content by $\mathrm{NaCl}$ treatment, Chichen-Itza variety exhibited much higher $\mathrm{Na}^{+} / \mathrm{K}^{+}$ratio in roots compared to the Rex variety (Figure $4 \mathrm{~F}$ ). In contrast, the $\mathrm{Na}^{+} / \mathrm{K}^{+}$ratio in
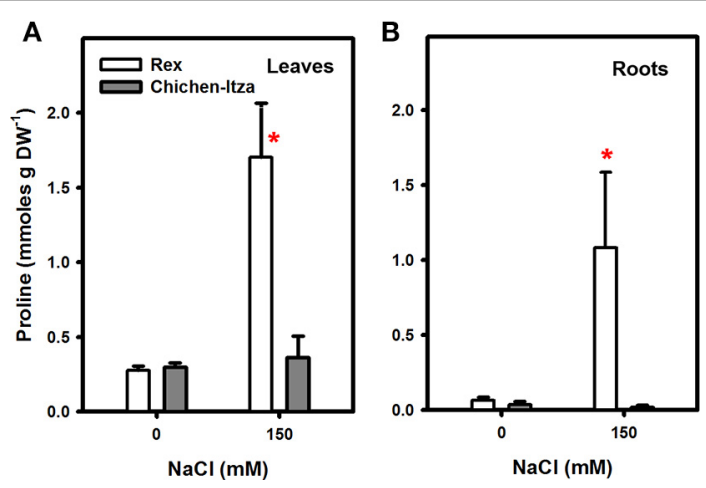

FIGURE 3 | Effect of $\mathrm{NaCl}$ treatment on proline accumulation in leaves (A) and roots (B) of two varieties of $\boldsymbol{C}$. chinense. The bars (white: Rex, gray: Chichen-Itza) represent the means of treatments with or without $\mathrm{NaCl}$ $(150 \mathrm{mM}), \mathrm{ME} \pm \mathrm{SD}(n=3)$. The asterisk indicates statistically significant differences between varieties for each treatment ( $P<0.050$, Tukey's test). leaves at $\mathrm{NaCl}$ treatment did not differ between the genotypes (Figure 4C). Furthermore, at low and moderate concentrations of $\mathrm{NaCl}$, the Rex variety exhibited higher $\mathrm{Na}^{+}$content in the roots and much lower $\mathrm{Na}^{+}$content in the leaves. The opposite effect was observed in the Chichen-Itza variety at $50 \mathrm{mM} \mathrm{NaCl}$. Similar $\mathrm{Na}^{+}$content was observed between shoots and roots at a concentration of $100 \mathrm{mM}$ (Figure S2).

\section{NaCI INDUCES K ${ }^{+}$EFFLUX IN ROOTS OF C. CHINENSE}

As described so far, Chichen-Itza and Rex varieties differ in their sensitivity to salt stress, the latter being less affected (Figures 1, 2 ). The Rex variety retains $55 \%$ of $\mathrm{K}^{+}$in salt-stress conditions, whereas Chichen-Itza looses about $90 \%$ of the root $\mathrm{K}^{+}$(Figure 4). To deepen the study of this response, the $\mathrm{K}^{+}$flux was measured using the non-invasive MIFE technique. The addition of $150 \mathrm{mM}$ $\mathrm{NaCl}$ induced $\mathrm{K}^{+}$efflux from the epidermal cells in the mature root zone of the two varieties of $C$. chinense (Figure 5). This efflux started immediately following $\mathrm{NaCl}$ treatment. A higher $\mathrm{K}^{+}$efflux was observed in the roots of the Chichen-Itza variety compared to Rex variety (Figure 5A). The difference in $\mathrm{K}^{+}$efflux in the $1 \mathrm{~min}$ was double and the relative difference even increased with time (Figure 5B). In the Rex variety $\mathrm{K}^{+}$efflux was close zero after $35 \mathrm{~min}$, whereas in Chichen-Itza a significant $\mathrm{K}^{+}$efflux of about $50 \mathrm{nmol} \mathrm{m}^{-2} \mathrm{~s}^{-1}$ was observed at late times.

\section{EFFECT OF NaCI ON H+ EFFLUX IN ROOTS OF C. CHINENSE}

In the roots of habanero pepper, $\mathrm{NaCl}$ stress caused significant changes in the net flux of $\mathrm{H}^{+}$(Figure 6). Before starting the salt treatment (first $5 \mathrm{~min}$ ), the net flux of $\mathrm{H}^{+}$was zero in both varieties. Application of $150 \mathrm{mM} \mathrm{NaCl}$ induced a substantial $\mathrm{H}^{+}$efflux (Figure 6A). In the roots of the Rex variety, $\mathrm{NaCl}$ induced $\mathrm{H}^{+}$efflux was much lower as compared the Chichen-Itza variety (Figure 6B). Furthermore, a pre-treatment

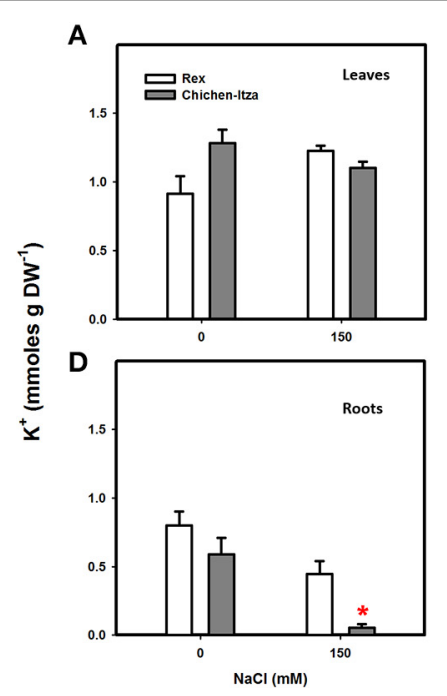

FIGURE 4 | Potassium and sodium content in two varieties of C. chinense under $\mathrm{NaCl}$ stress conditions. Forty-five-day-old seedlings cultivated in hydroponic cultures $(\mathrm{H} 1 / 5)$ for 7 days with 0 and $150 \mathrm{mM}$ of $\mathrm{NaCl} . \mathrm{K}^{+}$content in the leaves (A) and roots (D) of Rex and Chichen-Itza varieties after treatment with salt. $\mathrm{Na}^{+}$content in the leaves (B) and roots
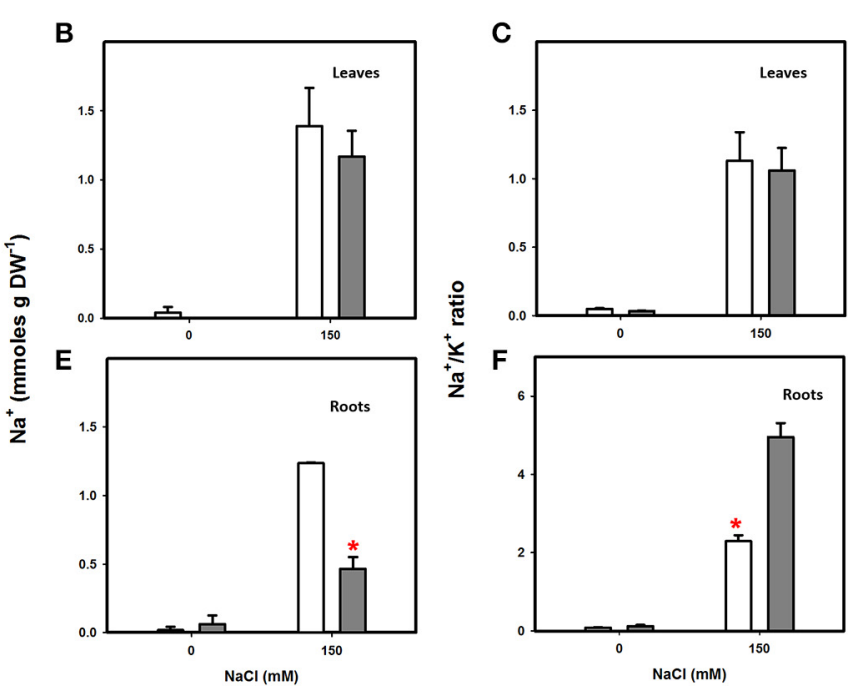

(E) of the two $C$. chinense varieties after 7 days of treatment. The $\mathrm{Na}^{+} / \mathrm{K}^{+}$ ratios in leaves $(\mathbf{C})$ and roots $(\mathbf{F})$ in control and $\mathrm{NaCl}$ treatments. Bars represent the average of the treatments with or without $\mathrm{NaCl}(150 \mathrm{mM})$, $\mathrm{ME} \pm \mathrm{SD}(n=3)$. The asterisk indicates statistically significant differences between varieties for each treatment ( $P<0.050$, Tukey's test). 


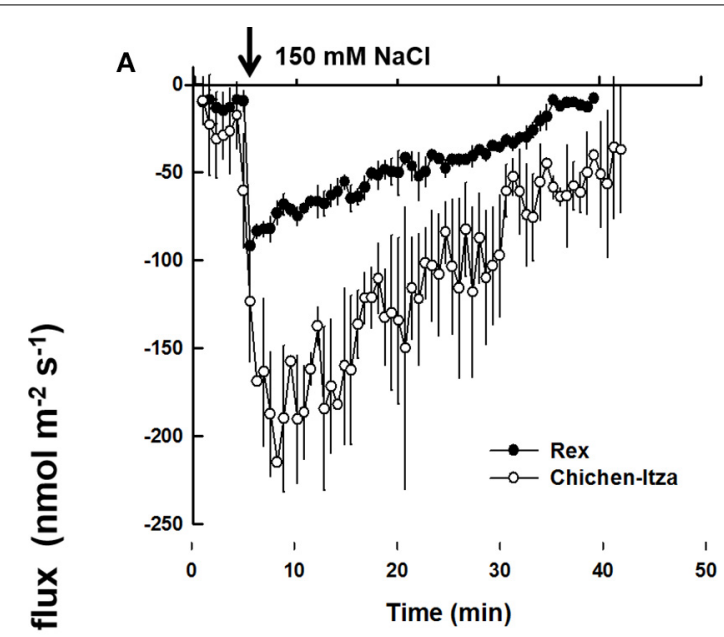

B

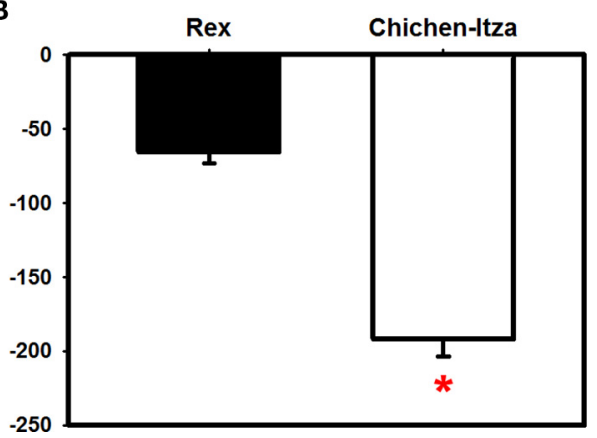

FIGURE 5 | Measurement of the net flow of $\mathrm{K}^{+}$in the roots of C. chinense in response to $\mathbf{N a C l}$ stress. (A) Kinetics of net $\mathrm{K}^{+}$flux measured in the mature root zone of seedlings (10 days old) of the Rex (closed circles) and Chichen-Itza (open circles) varieties in response to $150 \mathrm{mM} \mathrm{NaCl}$ (the arrow indicates the time of addition of the treatment) (B) Mean net flow of $\mathrm{K}^{+}$from the root of each variety in the first $10 \mathrm{~min}$ after application of $150 \mathrm{mM} \mathrm{NaCl}$. ME $\pm \mathrm{SD}(n=4-5)$. The asterisk indicates statistically significant differences between varieties by treatment $(P<0.001$, Tukey's test).

of seedlings with $1 \mathrm{mM}$ sodium orthovanadate (an inhibitor of P-type $\mathrm{H}^{+}$-ATPases) strongly suppressed the $\mathrm{H}^{+}$efflux from the mature root zone of both genotypes (Figure 7). Thus, the $\mathrm{NaCl}$ induced $\mathrm{H}^{+}$efflux was mediated by P-type $\mathrm{H}^{+}$-ATPases.

\section{$\mathrm{Na}^{+}$SUBCELLULAR LOCALIZATION IN ROOTS}

After 60 min of treatment with $150 \mathrm{mM} \mathrm{NaCl}$, marked differences were observed with respect to $\mathrm{Na}^{+}$localization in the mature root zone between two pepper genotypes (Figure 8). In the Rex variety, Sodium Green ${ }^{\mathrm{TM}}$ fluorescence was observed in vacuole-like structures of epidermal cells (red arrowheads, Figure 8A), suggesting an efficient mechanism for sodium compartmentalization in this variety. By contrast, in the Chichen-Itza variety, green fluorescence was observed around the epidermal cells in the mature root zone (white arrowheads, Figure 8B). Small endosomes stained with FM4-64 dye were observed in both pepper varieties under salt stress (yellow arrowheads, Figure 8). However, green fluorescence was not evident in these structures, indicating the absence of $\mathrm{Na}^{+}$accumulation (merge, Figure 8). In epidermal cells of the

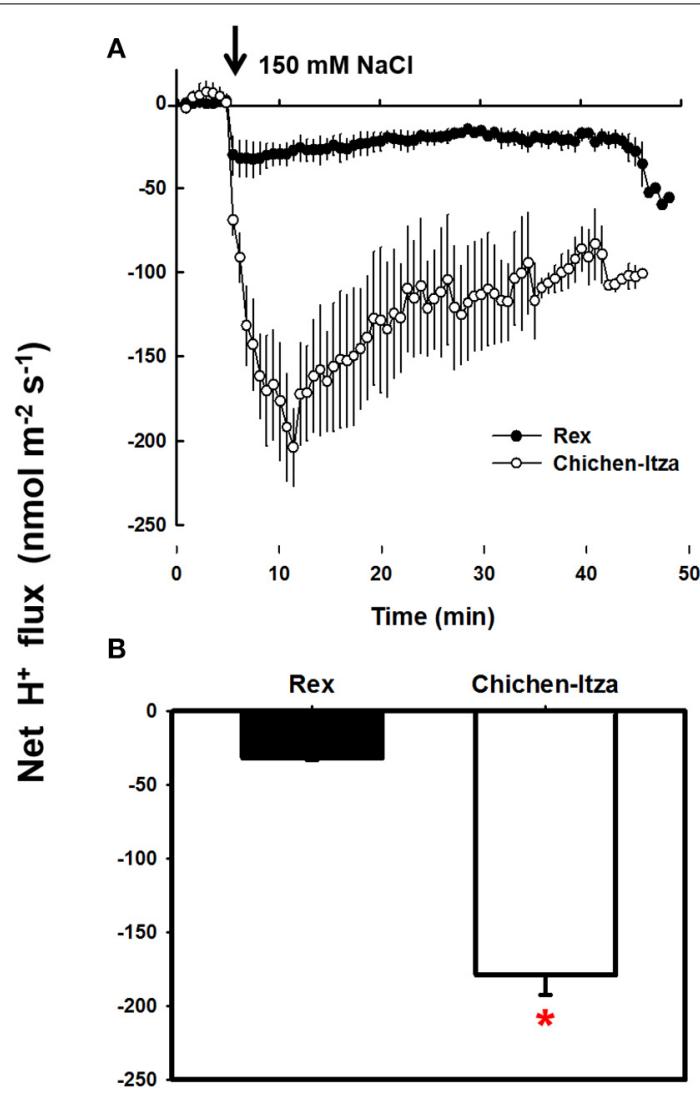

FIGURE 6 | Effect of $\mathrm{NaCl}$ on the net $\mathrm{H}^{+}$flux in the mature root area of C. chinense. (A) Kinetics of net flux of $\mathrm{H}^{+}$measured in the roots of 10-day-old seedlings of Rex (closed circles) and Chichen-Itza (open circles) varieties after adding $150 \mathrm{mM} \mathrm{NaCl}$ (arrow indicates the time addition of the treatment). (B) Mean net flow of $\mathrm{H}^{+}$from the root of each variety within the first $10 \mathrm{~min}$ of application of $150 \mathrm{mM} \mathrm{NaCl}$. ME $\pm \mathrm{SD}(n=4-5)$. The asterisk indicates statistically significant differences between varieties by treatment $(P<0.001$, Tukey's test).

Rex variety, a conglomeration of small structures with green fluorescence was observed around a larger structure comparable to a vacuole (red arrowheads, Figure 9A); similar structures were previously observed in Arabidopsis (Hamaji et al., 2009). In contrast to the Rex variety, in the Chichen-Itza a less pronounced and diffuse pattern of small compartments stained with Sodium Green $^{\mathrm{TM}}$ was observed (red arrowheads, Figure 9A). Overall, the highest levels of fluorescence were observed outside the cells in Chichen-Itza (white arrowheads, Figure 9B), demonstrating that $\mathrm{Na}^{+}$was mainly located in the apoplast. In control roots, $\mathrm{Na}^{+}$ indicator did not report any change of fluorescence for either variety (Figure S3).

\section{DISCUSSION}

\section{SENSITIVITY AND GROWTH IN C. CHINENSE SEEDLINGS UNDER NaCI} STRESS

Most crop plants that provide food for the world population are glycophytes and are very sensitive to high concentrations of salts in the soil, mainly $\mathrm{NaCl}$. Salt stress is the main abiotic factor that affects growth, yield, and quality. Peppers (Capsicum spp.) 

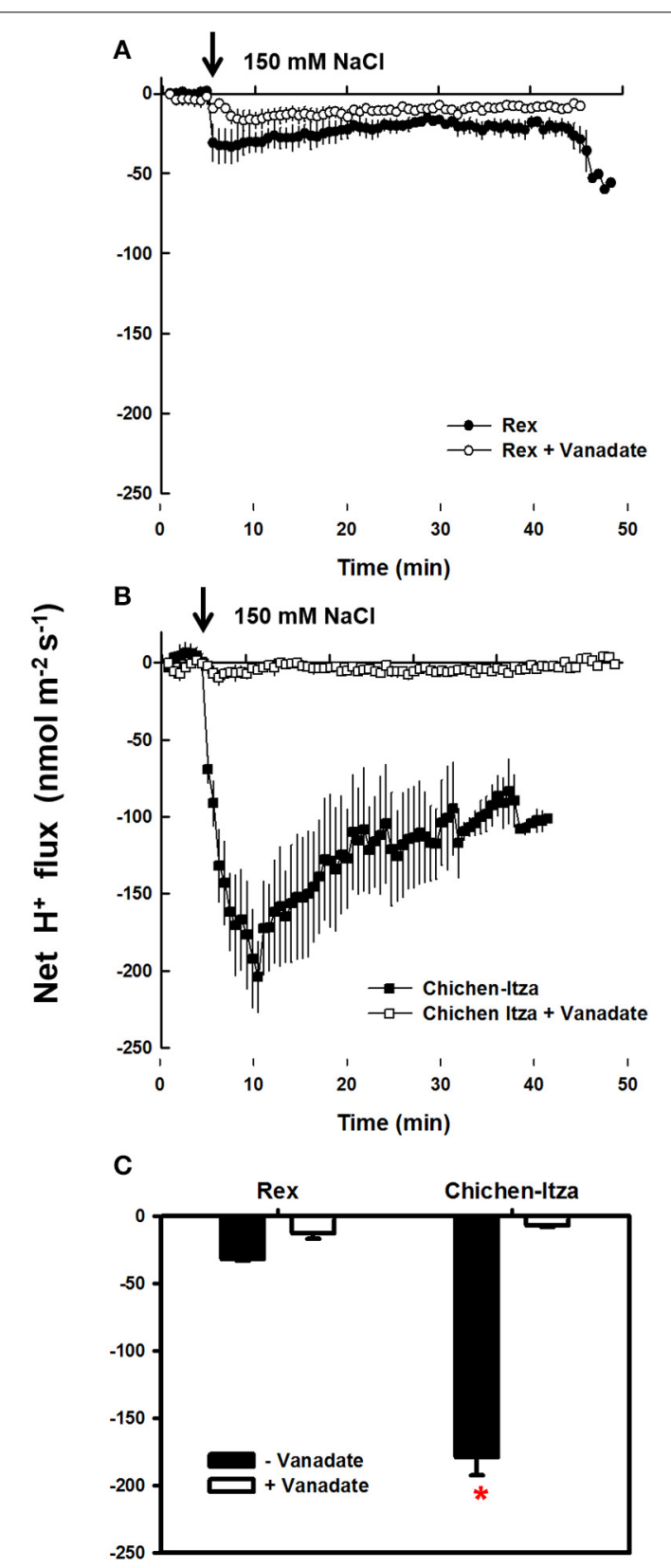

FIGURE 7 | Effect of vanadate pre-treatment on $\mathrm{NaCl}$-induced $\mathrm{H}^{+}$efflux in roots of $\boldsymbol{C}$. chinense. (A) Kinetics of net $\mathrm{H}^{+}$flux measured in the mature root zone of the Rex variety and (B) of the Chichen-Itza variety. 10-day-old roots of the two strains were pre-treated with $1 \mathrm{mM}$ vanadate for 45-60 min before adding of $150 \mathrm{mM} \mathrm{NaCl}$ (marked by an arrow). Open circles and squares indicate pre-treatment with vanadate. Closed circles and squares indicate no pre-treatment. (C) Average effect of vanadate pre-treatment on the net flow of $\mathrm{H}^{+}$from the root of each variety in the first $10 \mathrm{~min}$ after the application of $150 \mathrm{mM} \mathrm{NaCl}, \mathrm{ME} \pm \mathrm{SD}(n=3-4)$. The asterisk indicates statistically significant differences between varieties by treatment $(P<0.001$, Tukey's test).

are a major vegetable crop and are not exempt from the effect of salt throughout their ontogeny (Bojórquez-Quintal et al., 2012). Notably, pepper plants differ in their sensitivity to salt stress, including marked differences between varieties within the same species (Aktas et al., 2006). In this work, two varieties of C. chinense Jacq. were used as models. C. chinense Jacq. is a species in high demand in southeastern Mexico for its flavor and pungency and is commonly known as habanero pepper. These varieties exhibit different morphological characteristics and were shown to differ in their sensitivity to salt stress, with the Rex variety being more tolerant than the Chichen-Itza variety (Figure 1).

$\mathrm{NaCl}$ concentrations between 0 and $150 \mathrm{mM}$ affect the growth of pepper plants, depending on the genotype, species, and condition of growth (Bojórquez-Quintal et al., 2012). In this study, the application of $150 \mathrm{mM} \mathrm{NaCl}$ had a dramatic impact on the growth of both varieties of $C$. chinense. Similar results were reported in C. annuum (Aktas et al., 2006). The FW, turgor, and water content of the Rex variety were less affected (Figure 2). In this variety, $70 \%$ of seedlings survived after treatment with $\mathrm{NaCl}$, compared with $10 \%$ of the Chichen-Itza variety (data not shown). These results suggest the existence of intrinsic mechanisms of tolerance in the Rex variety to avoid the deleterious effect of $\mathrm{NaCl}$.

\section{DIFFERENCES IN PROLINE ACCUMULATION BETWEEN VARIETIES OF HABANERO PEPPERS}

Proline accumulation is one of the most common and important responses of plants to adverse environmental factors such as drought and salt stress. Proline is a multifunctional amino acid participating in a wide range of functions (Szabados and Savouré, 2009) and represents a potential biochemical marker for the salt tolerance in plants (Ashraf and Harris, 2004). In our study, different proline content was observed in two pepper varieties, contrasting in their salt sensitivity (Figure 3). In leaves of the Rex variety, proline content increased six times in the presence of $\mathrm{NaCl}$, as compared to a non-significant increase in ChichenItza leaves. The leaves are the major site of proline synthesis (source organ). It has been suggested that proline accumulation in this organ occurs to maintain chlorophyll content and turgor to protect the photosynthetic activity under salt stress conditions (Yildiztugay et al., 2011; Huang et al., 2013). Furthermore, treatment with $\mathrm{NaCl}$ induced a dramatic (16-fold) increase in proline content in the roots, but only of the tolerant variety Rex. At low water potential, proline is thought to be transported from the leaf (source) to the roots (sink) for growth processes or other functions, such as osmotic adjustment depending on proline content (Sharma et al., 2011). Exogenous administration of proline reduced $\mathrm{NaCl}$ - induced $\mathrm{K}^{+}$efflux in barley and Arabidopsis roots (Cuin and Shabala, 2005, 2007a,b). In Solanaceae such as the potato (S. tuberosum), increased proline content correlates with a higher expression of P5CS (synthesis gene) and decreased $P D H$ gene expression (degradation) in tolerant but not in sensitive cultures (Jaarsma et al., 2013). Furthermore, overexpression of P5CS in N. tabacum and S. tuberosum stimulated proline accumulation under $\mathrm{NaCl}$ stress and improved the tolerance (Kishore et al., 1995; Hmida-Sayari et al., 2005). However, there is not always a good correlation between the accumulation of this osmolyte and tolerance to salt stress, and whether it is a symptom of damage or an indicator of tolerance is a matter of debates. For example, in rice (O. sativa), soybean (G. max), tomato (S. lycopersicum), and barley ( $H$. vulgare), a negative correlation between proline accumulation and tolerance to stress has been reported. In these 

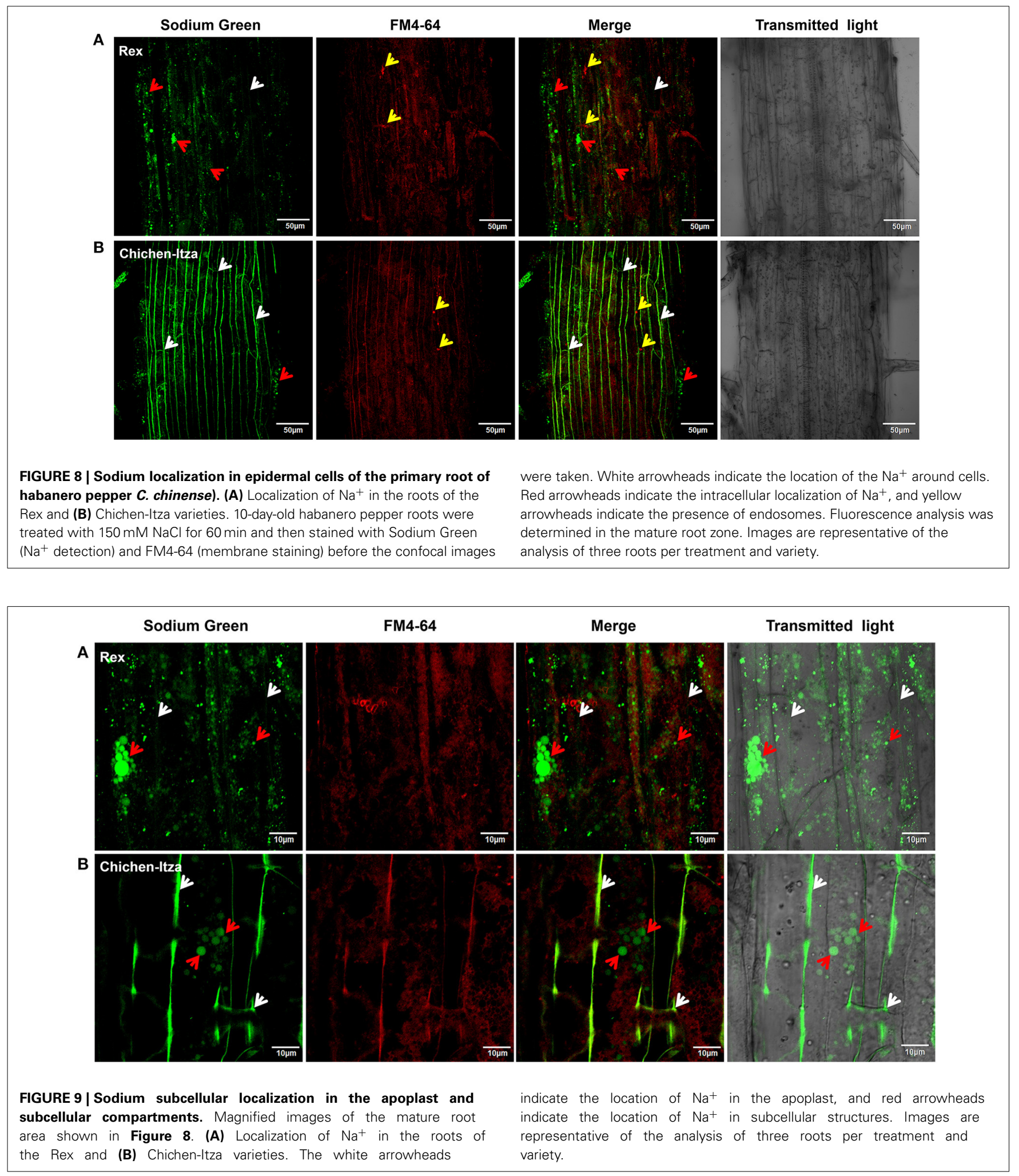

studies, sensitive genotypes accumulated more proline (Moftah and Michel, 1987; Aziz et al., 1998; Lutts et al., 1999; Chen et al., 2007a). In addition, proline synthesis is a metabolically expensive strategy (Shabala and Cuin, 2007; Shabala and Shabala, 2011).
Nevertheless, proline content has been shown to be higher in many plant varieties tolerant to salt relative to their susceptible counterparts (Ashraf and Harris, 2004), as also demonstrated by the results of this work (Figure 3). 


\section{THE TOLERANT PEPPER VARIETY ACCUMULATES MORE SODIUM IN THE ROOTS THAN THE SENSITIVE VARIETY}

The hyperaccumulation of $\mathrm{Na}^{+}$, particularly in the leaves, inhibits protein synthesis, enzymatic activity, and photosynthesis. Therefore, plants have the ability to control the transport and distribution of $\mathrm{Na}^{+}$to organs, tissues and cells where it causes less damage to protect against the accumulation of this cation. The most sensitive glycophytes (cereals or vegetables) are unable to control the transport of $\mathrm{Na}^{+}$; therefore, large amounts of this ion are translocated to the shoot (Maathuis, 2014), inducing senescence, growth inhibition, and eventually death of the plant (Roy et al., 2014). In contrast, most halophyte and some glycophytes plants tend to accumulate large amounts of $\mathrm{Na}^{+}$in the leaves. It has been suggested that these plants use $\mathrm{Na}^{+}$in addition to $\mathrm{K}^{+}$ to maintain turgor and growth (Hariadi et al., 2011; Adolf et al., 2013; Bonales-Alatorre et al., 2013a,b; Maathuis, 2014).

In our study (Figure 4), we observed that two varieties of habanero pepper (C. chinense) exhibit the same $\mathrm{Na}^{+}$content in the leaves but exhibit differences in $\mathrm{Na}^{+}$accumulation in the roots (after a minimum of 7 days of exposure to $150 \mathrm{mM} \mathrm{NaCl}$ ). In plants of $C$. annuum treated with $\mathrm{NaCl}$, a higher $\mathrm{Na}^{+}$content has been reported in the shoots of sensitive genotypes compared to tolerant genotypes. In fact, a positive correlation was observed between the severity of the symptoms in the leaves and $\mathrm{Na}^{+}$concentrations in the shoots (Aktas et al., 2006). This suggests an effect dependent on the accumulation of $\mathrm{Na}^{+}$as proposed Roy et al. (2014). The senescence and the severity of the symptoms observed in the aerial part of Capsicum chinense in this study (Figure 1) seem to be due to an osmotic effect rather than an ionic effect due to the presence of $\mathrm{Na}^{+}$in leaves (Figure 4B). In addition, this osmotic effect can be avoided by the accumulation of proline in the Rex variety (Figure 3A) as described in the previous section, as the effect of $\mathrm{NaCl}$ was less severe in that variety.

The root system is the first site of detection and the first line of defense against excess $\mathrm{Na}^{+}$in cells (Ji et al., 2013). NSCC are the principal source of $\mathrm{Na}^{+}$influx in the plant cell (Demidchik and Tester, 2002). As suggested for other species (Demidchik and Maathuis, 2007), NSCC can mediate $\mathrm{Na}^{+}$influx of pepper plants (Rubio et al., 2003). In our study, the Rex variety, less affected by salt, exhibited a two-fold higher $\mathrm{Na}^{+}$content in the root than in the Chichen-Itza variety (Figure 4E). Furthermore, the accumulation of $\mathrm{Na}^{+}$in the root system of the tolerant variety was higher at low $\mathrm{NaCl}$ concentrations $(50 \mathrm{mM})$ where reached its peak and was maintained at higher $\mathrm{NaCl}$ concentrations (150 mM). The levels of $\mathrm{Na}^{+}$in the roots of the Chichen-Itza variety were lower and stable at all of the $\mathrm{NaCl}$ concentrations tested (Figure S2). Overall, the accumulation of $\mathrm{Na}^{+}$is higher (in both roots and leaves) in the tolerant variety than in the sensitive variety (Figure S1 and Figure 4). At low and moderate salt concentration ranges, the Rex variety (tolerant) possesses more $\mathrm{Na}^{+}$in the roots and much less in the leaves. However, the opposite was observed in the Chichen-Itza variety (sensitive) at $50 \mathrm{mM}$ $\mathrm{NaCl}$. Furthermore, at $100 \mathrm{mM} \mathrm{NaCl}$, the same $\mathrm{Na}^{+}$content was observed between the shoots and roots in the Chichen-Itza variety (Figure S2). The higher $\mathrm{Na}^{+}$content in roots than in leaves suggests that exclusion mechanisms (SOS1, antiporters, and HKT1 transporters) and compartmentalization (NHX, antiporters) are present in roots and efficiently reduce the $\mathrm{Na}^{+}$transport to leaves. These mechanisms have also been reported in other members of Solanaceae, such as tomatoes and potatoes (Queirós et al., 2009; Rodríguez-Rosales et al., 2009; Almeida et al., 2014). In particular, the HKTs (subfamily 1) exhibit an important role in the recovery of $\mathrm{Na}^{+}$from the xylem to prevent its transport to the aerial part, and recirculate $\mathrm{Na}^{+}$to the roots (Horie et al., 2009; Almeida et al., 2013; Adams and Shin, 2014).

\section{$\mathrm{Na}^{+}$SUBCELULAR LOCALIZATION IN THE ROOTS: COMPARTMENTALIZATION AND Na+ EFFLUX IN DIFFERENT VARIETIES OF C. CHINENSE}

After 60 min of treatment with $150 \mathrm{mM} \mathrm{NaCl}, \mathrm{Na}^{+}$was mainly located in vacuole-like structures in root epidermal cells in the Rex variety (Figure 9). This result suggests the existence of an efficient mechanism for $\mathrm{Na}^{+}$compartmentalization in this genotype. Similarly, it has been reported that $\mathrm{Na}^{+}$is confined in epidermal cells vacuoles and in the cortex in the roots of Arabidopsis and Citrus (Oh et al., 2009; Gonzalez et al., 2012). Furthermore, it is noteworthy that in the two varieties of habanero pepper, small compartments were stained with the fluorophore. These compartments were found in greater quantities in the roots of the Rex variety (Figure 9). Similar results were observed in the roots of A. thaliana under salt stress. Hamaji et al. (2009) reported that $\mathrm{Na}^{+}$accumulates in the vacuoles as well as in small vesicular compartments around vacuoles. These authors suggest that the fusion of these vesicles with the main vacuole increases its size and the tolerance to excess salt. This explanation is logical, as we observed a conglomeration of structures stained with the fluorophore in the roots of the tolerant variety after a short period of $\mathrm{NaCl}$ stress (Figure 9). In tolerant salt includes such as mangroves and barley, a rapid increase in vacuolar volume in response to salt stress was observed. This phenomenon was not reported in sensitive species such as peas and tomatoes (Mimura et al., 2003).

Recently, in tobacco salt-acclimated BY2 cells accumulation of $\mathrm{Na}^{+}$in vacuoles and small vesicles was reported. Interestingly, the putative VAMP711 (vesicle-associated membrane protein 711) and VPS46 (charged multivesicular body protein) proteins were highly induced in this BY2 cells, suggesting a $\mathrm{Na}^{+}$transport mechanism for vesicle trafficking (Garcia de la Garma et al., 2014). Furthermore, the increased $\mathrm{Na}^{+}$sequestration by vacuolar and small compartments in the Rex variety could be due to increased expression of NHX transporters as observed in tomato species with different sensitivity to salt (Galvez et al., 2012). Also, the up-regulation of V-ATPase (vacuolar-type $\mathrm{H}^{+}$-ATPase) and $\mathrm{H}^{+}$-PPase (vacuolar $\mathrm{H}^{+}$-pyrophosphatase) in Rex variety may result in a higher proton electrochemical gradient, which facilitates enhanced sequestering of ions into the vacuole and endosomes, reducing water potential and resulting in increased salt tolerance (Gaxiola et al., 2001; Bassil et al., 2012; Pittman, 2012). In different species of plants, overexpression of AVP1 (vacuolar $\mathrm{H}^{+}$. PPase) and co-overexpression with AtNHX1 enhances salt tolerance (Gaxiola et al., 2001; Pasapula et al., 2011; Shen et al., 2014). Finally, the reduction of $\mathrm{Na}^{+}$loss via non-selective vacuolar channels could assist efficient vacuolar $\mathrm{Na}^{+}$accumulation (BonalesAlatorre et al., 2013b). In the Rex variety, all or some of these mechanisms may be involved in the $\mathrm{Na}^{+}$compartmentalization. 
On the contrary, in the Chichen-Itza variety, $\mathrm{Na}^{+}$was mostly observed in the apoplastic area between cells of the root (Figures 8, 9). This result suggests an intensive $\mathrm{Na}^{+}$extrusion toward the outside of the cell, likely via the $\mathrm{Na}^{+} / \mathrm{H}^{+}$antiporters (SOS1) of the plasma membrane (Shi et al., 2002). This is consistent with a low content of $\mathrm{Na}^{+}$(Figure 4) and with the large active $\mathrm{H}^{+}$efflux, mediated by vanadate-sensitive $\mathrm{H}^{+}$-ATPase, in the roots of this variety. However, the high rate of $\mathrm{Na}^{+}$extrusion in sensitive cultivars could have a high energetic cost (Malagoli et al., 2008). This opts for the use of intracellular $\mathrm{Na}^{+} / \mathrm{H}^{+}(\mathrm{NHX}-$ type) antiporters as compared to SOS1-type ones; the latter may be more useful in early responses to acute salt stress. Candidate genes for the intracellular (NHX) and plasma membrane (SOS1) exchangers were revealed in the genome of Capsicum annuum (Qin et al., 2014).

Furthermore, we may not exclude at this moment that accumulation of the indicator at cell walls, which possess high esterase activity, could contribute to the observed fluorescence signal and the difference between Rex and Chichen-Itza.

\section{$\mathrm{K}^{+}$RETENTION IN THE ROOTS IS A TOLERANCE MECHANISM IN HABANERO PEPPER PLANTS}

Potassium is an essential nutrient throughout the life cycle of plants, including the adaptation to hostile environments. The regulation of $\mathrm{K}^{+}$homeostasis plays a central role in tolerance to biotic and abiotic stresses in plants (Anschütz et al., 2014; Demidchik, 2014; Shabala and Pottosin, 2014). $\mathrm{K}^{+}$efflux from the root is a common physiological reaction that occurs under a wide range of stress conditions (Demidchik, 2014). $\mathrm{K}^{+}$retention in roots has been proved to confer salt tolerance in barley, wheat, lucerne, and poplar (Chen et al., 2007b,c; Cuin et al., 2008; Smethurst et al., 2008; Sun et al., 2009). In this study, the treatment with $150 \mathrm{mM} \mathrm{NaCl}$ significantly decreased the content of $\mathrm{K}^{+}$in the roots of the sensitive variety but not in the tolerant variety of habanero pepper (Figure 4D). In contrast, $\mathrm{K}^{+}$content in the leaves was not affected by treatment with $\mathrm{NaCl}$ in either genotype (Figure 4A). These data suggest that the ability to retain $\mathrm{K}^{+}$by roots is one of the salt tolerance mechanisms of $C$. chinense.

Initial $\mathrm{NaCl}$ induced $\mathrm{K}^{+}$efflux was higher in the ChichenItza as compared to the Rex variety and doubled after $10 \mathrm{~min}$ of exposure to $\mathrm{NaCl}$. Similar differences in $\mathrm{K}^{+}$efflux have been reported in barley ( $H$. vulgare), wheat (T. aestivum) and alfalfa (M. sativa). This difference has been used as a selection criterion to distinguish salt-tolerant from salt-sensitive genotypes (Chen et al., 2005, 2007b,c; Smethurst et al., 2008), yet some plants, like rice, did not show such a correlation (Coskun et al., 2013). In our results, content and $\mathrm{K}^{+}$efflux in roots (Figures 4,5 ) were consistent with the observed differences in sensitivity between the varieties of habanero pepper (Figures 1, 2).

$\mathrm{NaCl}$-induced $\mathrm{K}^{+}$efflux may be through outward-rectifying $\mathrm{K}^{+}$(KOR) channels activated by depolarization as demonstrated in barley (H. vulgare) and mangrove species (Chen et al., 2007b; Sun et al., 2009; Lu et al., 2013). The use of ion channels inhibitors in habanero pepper indicate that $\mathrm{K}^{+}$efflux from the roots are likely mediated by KOR channels rather than by NSCC channels (Bojorquez-Quintal et al., in review). Furthermore, ROS and $\mathrm{K}^{+}$deficiency have been associated with programmed cell-death
(PCD) and necrosis (Anschütz et al., 2014; Demidchik, 2014; Shabala and Pottosin, 2014). Necrosis was observed in the roots of the Chichen-Itza variety (Figure 1), which have low ability to retain $\mathrm{K}^{+}$(Figures 4, 5).

\section{DIFFERENCES IN H ${ }^{+}$EFFLUX IN THE ROOTS OF HABANERO PEPPER UNDER NaCI STRESS}

$\mathrm{H}^{+}$-ATPases generate an electrochemical gradient that maintains membrane potential and transports ions between the cytosol and the external medium. Under salt stress, $\mathrm{NaCl}$ universally induces $\mathrm{H}^{+}$efflux in the roots of cereals such as $H$. vulgare and T. aestivum, halophytes such as C. quinoa and even in the model plant A. thaliana (Chen et al., 2007b; Cuin et al., 2008; Hariadi et al., 2011; Bose et al., 2013, 2014). In C. chinense, $\mathrm{NaCl}$ also induced $\mathrm{H}^{+}$efflux in the mature root zone. $\mathrm{H}^{+}$flux differed significantly between the varieties (Figure 6). $\mathrm{NaCl}$ rapidly induced the $\mathrm{H}^{+}$ efflux in both varieties of habanero peppers. It was suppressed by vanadate, the inhibitor of P-type $\mathrm{H}^{+}$-ATPase (Figure 7). $\mathrm{H}^{+}$ pumping activity of the plasma membrane $\mathrm{H}^{+}$-ATPase is essential for salt tolerance (Palmgren and Nissen, 2010). It has been suggested that the ability to $\mathrm{K}^{+}$retain is related to the increase in $\mathrm{H}^{+}$-ATPase activity, primarily through a membrane potential repolarization (Bose et al., 2013, 2014).

Maintaining a more negative membrane potential during salt stress prevents the loss of $\mathrm{K}^{+}$in the cytosol. In the salttolerant Arabidopsis relative species, T. halophila, a more negative membrane potential, correlated with a better $\mathrm{K}^{+}$retention, was observed during salt stress (Volkov and Amtmann, 2006). In transgenic $A$. thaliana ( $\mathrm{HO}$, heme oxygenase), $\mathrm{K}^{+}$retention was regulated by the increased $\mathrm{H}^{+}$-ATPase activity (Bose et al., 2013). A higher $\mathrm{H}^{+}$-ATPase activity maintained a more negative membrane potential and improved $\mathrm{K}^{+}$retention in tolerant genotypes of $H$. vulgare (Chen et al., 2007b). In contrast, higher $\mathrm{H}^{+}$transport activity was observed in the sensitive variety Chichen-Itza of C. chinense (Figure 6). Kinetics and magnitude of the $\mathrm{H}^{+}$efflux coincides with that of the $\mathrm{K}^{+}$efflux (Figure 5). Thus, it may be hypothesized that the descending phase of the $\mathrm{H}^{+}$efflux reflects the condition of membrane potential repolarization, so that the leakage of $\mathrm{K}^{+}$through KOR channels would be also reduced.

Furthermore, the plasma membrane $\mathrm{H}^{+}$-ATPase activity provides the driving force the $\mathrm{Na}^{+}$extrusion via the $\mathrm{Na}^{+} / \mathrm{H}^{+}$(SOS1) exchanger. In this work, we observed a massive accumulation of $\mathrm{Na}^{+}$in the apoplast of the Chichen-Itza variety roots (Figure 9). These data suggest that SOS1 antiporter may be very active in the Chichen-Itza variety. However, $\mathrm{Na}^{+}$efflux has a high energetic cost for the cell, especially keeping in mind a futile $\mathrm{Na}^{+}$cycling between cytosol and apoplast. It may recruit the ATP available for other metabolic processes, thus, being detrimental to growth and yield. For this reason, the activation of $\mathrm{H}^{+}$-ATPase cannot be considered a permanent solution and might only be a temporal mechanism, as described by other studies (Ramani et al., 2006; Bose et al., 2013).

\section{POSSIBLE TOLERANCE MECHANISM IN PEPPERS}

Salt tolerance is a complex multigenic trait that involves many biochemical and physiological processes to achieve salt tolerance. In this paper, we demonstrate differences in salt sensitivity 


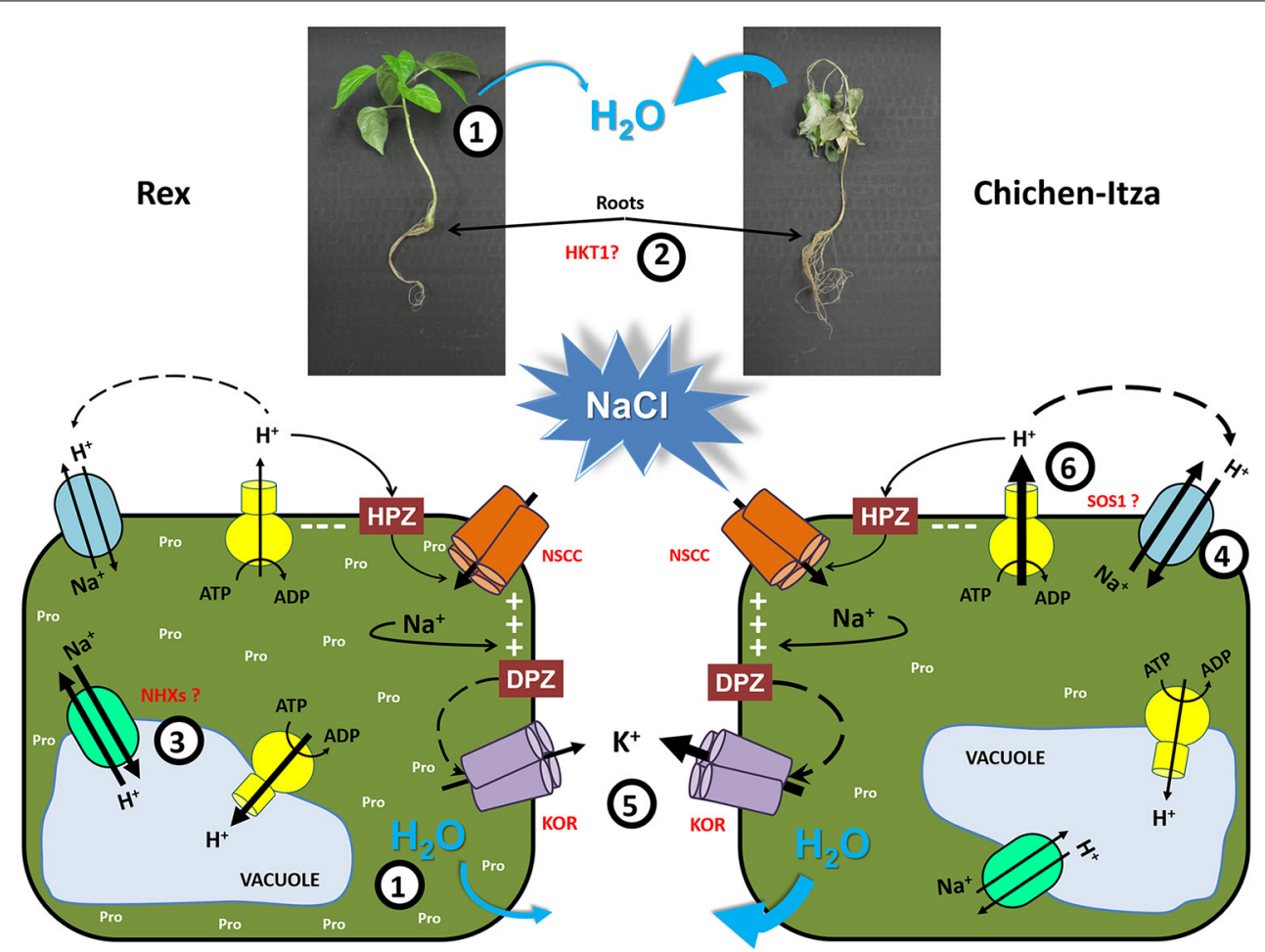

FIGURE 10 | Schematic model of habanero pepper plant tolerance mechanisms. (1) Osmotic adjustment through the accumulation of compatible solutes as proline in leaves and roots to maintain the absorption and prevent the loss of water. (2) Efficient control of $\mathrm{Na}^{+}$transport by confining this ion to roots, possibly through the recovery of $\mathrm{Na}^{+}$from the xylem by HKT1 transporters to avoid transport to photosynthetic tissues. (3) $\mathrm{Na}^{+}$compartmentalization in vacuole-like structures and small subcellular compartments, where it can act as an osmolyte, suggesting the involvement of vacuolar and endosomal NHX transporters. (4) $\mathrm{Na}^{+}$extrusion or efflux from the cytosol to the apoplast by SOS1 exchangers. (5) Regulation of $\mathrm{K}^{+}$ homeostasis through $\mathrm{K}^{+}$retention in roots is crucial in habanero peppers. (6) Increase in the $\mathrm{H}^{+}$-ATPase activity to generate the proton force for cell membrane repolarization or $\mathrm{Na}^{+}$extrusion. (KOR), outward-rectifying $\mathrm{K}^{+}$ channels. HPZ is hyperpolarization and DPZ is depolarization. between two varieties of $C$. chinense Jacq, one of the five domesticated pepper species. We have analyzed several parameters of salt stress responses in both genotypes and their differences that may underlie their differential salt tolerance (Figure 10). One of salt tolerance mechanisms is the osmotic adjustment through the accumulation of compatible solutes (in this case, proline) in roots and leaves to maintain the absorption and prevent the loss of water (1). A second tolerance mechanism is the efficient control of $\mathrm{Na}^{+}$transport by confining this ion to the roots, possibly through the recovery of $\mathrm{Na}^{+}$from the xylem by HKT1 transporters (at low, moderate and high concentration of $\mathrm{NaCl}$ ) to avoid transport to photosynthetic tissues (2). Furthermore, if the $\mathrm{Na}^{+}$content in roots is high, this ion needs to be excluded from the cytosol to avoid toxicity. A third tolerance mechanism was observed in the tolerant variety (Rex), $\mathrm{Na}^{+}$was efficiently compartmentalized into vacuole-like structures and small compartments which can act as osmolytes. This mechanism is possibly mediated by vacuolar and endosomal NHX antiporters (3). Additional mechanism appears to be involved in salt-sensitive variety (Chichen-Itza), which extrudes large amounts of $\mathrm{Na}^{+}$ into the apoplast (4). However, this mechanism appears to be less efficient due to its large energy cost. As in many other plant species, the regulation of $\mathrm{K}^{+}$homeostasis through its retention in roots is crucial in habanero peppers (5), demonstrating the universality of this mechanism to the salt stress tolerance of crops.

\section{ACKNOWLEDGMENTS}

For help with the confocal microscopy analysis we thank Luis Alberto Cruz Silva (Instituto de Ecología A.C.). We thank Lucila A. Sanchez Cach for their excellent technical assistance (Centro de Investigación Científica de Yucatán, A.C.). This work was supported by CONACYT project \# 166621.

\section{SUPPLEMENTARY MATERIAL}

The Supplementary Material for this article can be found online at: http://www.frontiersin.org/journal/10.3389/fpls.2014.00605/ abstract

Figure $\mathrm{S} 1 \mid \mathrm{K}^{+}$content of two varieties of $C$. chinense at different $\mathrm{NaCl}$ concentrations. $\mathrm{K}^{+}$content in the leaves (A) and roots (B) after treatment with salt. Forty-five-day-old seedlings cultivated in $\mathrm{H} 1 / 5$ for 7 days with 0 , 50,100 or $150 \mathrm{mM}$ of $\mathrm{NaCl}$. Bars represent averages for treatments with or without $\mathrm{NaCl}, \mathrm{ME} \pm \mathrm{SD}(n=3)$. The asterisk indicates statistically significant differences between varieties by treatment $(P<0.050$, Tukey's test).

Figure $\mathrm{S} 2 \mathrm{Na}^{+}$content in Rex and Chichen-Itza varieties at different $\mathrm{NaCl}$ concentrations. $\mathrm{Na}^{+}$content in the leaves (A) and roots (B) after 7 days 
under salt stress conditions. Forty-five-day-old seedlings were cultivated in $\mathrm{H} 1 / 5$ with $0,50,100$, and $150 \mathrm{mM}$ of $\mathrm{NaCl}$. Bars represent the average effect of the treatments with or without $\mathrm{NaCl}, \mathrm{ME} \pm \mathrm{SD}(n=3)$. The asterisk indicates statistically significant differences between varieties by treatment $(P<0.050$, Tukey's test).

\section{Figure S3 | Roots of control seedlings exhibit an absence of Sodium} Green $^{\mathrm{TM}}$ fluorescence. Roots of untreated Rex (A) and Chichen-Itza (B) varieties stained with Sodium Green (SG), FM4-64, and DAPI. Images are representative of the analysis of three roots per treatment and variety.

\section{REFERENCES}

Adams, E., and Shin, S. (2014). Transport, signalling, and homeostasis of potassium and sodium in plants. J. Integr. Plant Biol. 56, 231-249. doi: 10.1111/jipb.12159

Adem, G. D., Roy, S. J., Zhou, M., Bowman, J., and Shabala, S. (2014). Evaluating contribution of ionic, osmotic and oxidative stress components towards salinity tolerance in barley. BMC Plant Biol. 14:113. doi: 10.1186/1471-2229-14-113

Adolf, V. I., Jacobsen, S. E., and Shabala, S. (2013). Salt tolerance mechanisms in quinoa (Chenopodium quinoa Willd.). Environ. Exp. Bot. 92, 43-54. doi: 10.1016/j.envexpbot.2012.07.004

Aktas, H., Abak, K., and Cakmak, I. (2006). Genotypic variation in the response of pepper to salinity. Sci. Hortic. 110, 260-266. doi: 10.1016/j.scienta.2006.07.017

Almeida, P., de Boer, G.-J., and de Boer, A. H. (2014). Differences in shoot $\mathrm{Na}^{+}$ accumulation between two tomato species are due to differences in ion affinity of HKT1;2. J. Plant Physiol. 171, 438-447. doi: 10.1016/j.jplph.2013.12.001

Almeida, P., Katsching, D., and de Boer, A. H. (2013). HKT transporters-State of the art. Int. J. Mol. Sci. 14, 20359-20385. doi: 10.3390/ijms141020359

Anschütz, U., Becker, D., and Shabala, S. (2014). Going beyond nutrition: regulation of potassium homoeostasis as a common denominator of plant adaptive responses to environment. J. Plant Physiol. 171, 670-687. doi: 10.1016/j.jplph.2014.01.009

Apse, M. P., Aharon, G. S., Snedden, W. A., and Blumwald, E. (1999). Salt tolerance conferred by overexpression of a vacuolar $\mathrm{Na}^{+} / \mathrm{H}^{+}$antiport in Arabidopsis. Science 285, 1256-1258. doi: 10.1126/science.285.5431.1256

Apse, M. P., and Blumwald, E. (2007). $\mathrm{Na}^{+}$transport in plants. FEBS Lett. 581, 2247-2254. doi: 10.1016/j.febslet.2007.04.014

Ashraf, M., and Harris, P. J. C. (2004). Potential biochemical indicators of salinity tolerance in plants. Plant Sci. 166, 3-16. doi: 10.1016/j.plantsci.2003.10.024

Aziz, A., Martin-Tanguy, J., and Larher, F. (1998). Stress-induced changes in polyamine and tyramine levels can regulate proline accumulation in tomato leaf discs treated with sodium chloride. Physiol. Plant. 104, 195-202. doi: 10.1034/j.1399-3054.1998.1040207.x

Bassil, E., Coku, A., and Blumwald, E. (2012). Cellular ion homeostasis: emerging roles of intracellular $\mathrm{NHX} \mathrm{Na} / \mathrm{H}^{+}$antiporters in plant growth and development. J. Exp. Bot. 63, 5727-5740. doi: 10.1093/jxb/ers250

Bates, L. S., Waldren, R. P., and Teare, D. (1973). Rapid determination of free proline for water-stress studies. Plant Soil 39, 2005-2007. doi: 10.1007/BF00018060

Bojórquez-Quintal, J. E., Echevarría-Machado, I., Medina-Lara, F., and MartínezEstévez, M. (2012). Plants challenges in a salinized world: the case of Capsicum. Afr. J. Biotechnol. 11, 13614-13626. doi: 10.5897/AJB12.2145

Bonales-Alatorre, E., Pottosin, I., Shabala, L., Chen, Z.-H., Zeng, F., Jacobsen, S. E., et al. (2013a). Differential activity of plasma and vacuolar membrane transporters contributes to genotypic differences in salinity tolerance in a halophyte species, Chenopodium quinoa. Int. J. Mol. Sci. 14, 9267-9285. doi: 10.3390/ijms14059267

Bonales-Alatorre, E., Shabala, S., Chen, Z. H., and Pottosin, I. (2013b). Reduced tonoplast fast-activating and slow-activating channel activity is essential for conferring salinity tolerance in a facultative halophyte, quinoa. Plant Physiol. 162, 940-952. doi: 10.1104/pp.113.216572

Bose, J., Shabala, L., Pottosin, I., Zeng, F., Velarde-Buendía, A. M., Massart, A., et al. (2014). Kinetics of xylem loading, membrane potential maintenance, and sensitivity of $\mathrm{K}^{+}$-permeable channels to reactive oxygen species: physiological traits that differentiate salinity tolerance between pea and barley. Plant Cell Environ. 37, 589-600. doi: 10.1111/pce. 12180

Bose, J., Xie, Y., Shen, W., and Shabala, S. (2013). Haem oxygenase modifies salinity tolerance in Arabidopsis by controlling $\mathrm{K}^{+}$retention via regulation of the plasma membrane $\mathrm{H}^{+}$-ATPase and by altering SOS1 transcript levels in roots. J. Exp. Bot. 64, 471-481. doi: 10.1093/jxb/ers343
Chen, Z., Cuin, T. A., Zhou, M., Twomey, A., Naidu, B. P., and Shabala, S. (2007a). Compatible solute accumulation and stress-mitigating effects in barley genotypes contrasting in their salt tolerance. J. Exp. Bot. 58, 4245-4255. doi: $10.1093 /$ jxb/erm 284

Chen, Z., Newman, I., Zhou, M., Mendham, N., Zhang, G., and Shabala, S. (2005). Screening plants for salt tolerance by measuring $K+$ flux: a case study for barley. Plant Cell Environ. 28, 1230-1246. doi: 10.1111/j.1365-3040.2005. 01364.x

Chen, Z., Pottosin, I. I., Cuin, T. A., Fuglsang, A. T., Tester, M., Jha, D., et al. (2007b). Root plasma membrane transporters controlling $\mathrm{K}^{+} / \mathrm{Na}^{+}$homeostasis in salt-stressed barley. Plant Physiol. 145, 1714-1725. doi: 10.1104/pp.107. 110262

Chen, Z., Zhou, M., Newman, I. A., Mendham, N. J., Zhang, G., and Shabala, S. $(2007 \mathrm{c})$. Potassium and sodium relations in salinised barley tissues as a basis of differential salt tolerance. Funct. Plant Biol. 34, 150-162. doi: 10.1071/FP06237

Conn, S., and Gilliham, M. (2010). Comparative physiology of elemental distributions in plants. Ann. Bot. 105, 1081-1102. doi: 10.1093/aob/mcq027

Coskun, D., Britto, D. T., Jean, Y.-K., Kabir, I., Tolay, I., Torum, A. A., et al. (2013). $\mathrm{K}^{+}$efflux and retention in response to $\mathrm{NaCl}$ stress do not predict salt tolerance in contrasting genotypes of rice (Oryza sativa L.). PLoS ONE 8:e57767. doi: 10.1371/journal.pone.0057767

Cuin, T. A., Betts, S. A., Chalmandrier, R., and Shabala, S. (2008). A root's ability to retain $\mathrm{K}^{+}$correlates with salt tolerance in wheat. J. Exp. Bot. 59, 2697-2706. doi: $10.1093 /$ jxb/ern128

Cuin, T. A., and Shabala, S. (2005). Exogenously supplied compatible solutes rapidly ameliorate $\mathrm{NaCl}$-induced potassium efflux from barley roots. Plant Cell Physiol. 46, 1924-1933. doi: 10.1093/pcp/pci205

Cuin, T. A., and Shabala, S. (2007a). Amino acids regulate salinity-induced potassium efflux in barley root epidermis. Planta 225, 753-761. doi: 10.1007/s00425006-0386-X

Cuin, T. A., and Shabala, S. (2007b). Compatible solutes reduce ROS-induced potassium efflux in Arabidopsis roots. Plant Cell Environ. 30, 875-885. doi: 10.1111/j.1365-3040.2007.01674.x

Demidchik, V. (2014). Mechanism and physiological roles of $\mathrm{K}^{+}$efflux from root cells. J. Plant Physiol. 171, 696-707. doi: 10.1016/j.jplph.2014.01.015

Demidchik, V., and Maathuis, F. J. M. (2007). Physiological roles of nonselective cation channels in plants: from salt stress to signaling and development. New Phytol. 175, 387-404. doi: 10.1111/j.1469-8137.2007.02128.x

Demidchik, V., and Tester, M. (2002). Sodium fluxes through nonselective cation channels in the plasma membrane of protoplasts from Arabidopsis roots. Plant Physiol. 128, 379-387. doi: 10.1104/pp.010524

Flowers, T. J., and Colmer, T. D. (2008). Salinity tolerance in halophytes. New Phytol. 179, 945-963. doi: 10.1111/j.1469-8137.2008.02531.x

Galvez, F. J., Baghour, M., Hao, G., Cagnac, O., Rodriguez-Rosales, M. P., and Venema, K. (2012). Expression of LeNHX isoforms in response to salt stress in salt sensitive and salt tolerant tomato species. Plant Physiol. Biochem. 51, 109-115. doi: 10.1016/j.plaphy.2011.10.012

Garcia de la Garma, J., Fernandez-Garcia, N., Bardisi, E., Pallol, B., Asencio-Rubio, J. S., Bru, R., et al. (2014). New insights into plant salt acclimation: the roles of vesicle trafficking and reactive oxygen species signalling in mitochondria and the endomembrane system. New Phytol. doi: 10.1111/nph.12997. [Epub ahead of print].

Gaxiola, R. A., Li, J., Undurraga, S., Dang, L. M., Allen, G. J., Alper, S. L., et al. (2001). Drought- and salt-tolerant plants result from overexpression of the AVP1 H+pump. Proc. Natl. Acad. Sci. U.S.A. 98, 11444-11449. doi: 10.1073/pnas. 191389398

Gonzalez, P., Syvertsen, J. P., and Etxeberria, E. (2012). Sodium distribution in saltstressed Citrus Rootstock seedlings. HortScience 47, 1504-1511.

Hamaji, K., Nagira, M., Yoshida, K., Ohnishi, M., Oda, Y., Uemura, T., et al. (2009). Dynamic aspects of ion accumulation by vesicle traffic under salt stress in Arabidopsis. Plant Cell Physiol. 50, 2023-2033. doi: 10.1093/pcp/pcp143

Hariadi, Y., Marandon, K., Tian, Y., Jacobsen, S. E., and Shabala, S. (2011). Ionic and osmotic relations in quinoa (Chenopodium quinoa Willd.) plants grown at various salinity levels. J. Exp. Bot. 62, 185-193. doi: 10.1093/jxb/erq257

Hmida-Sayari, A., Gargouri-Bouzid, R., Bidani, A., Jaoua, L., Savouré, A., and Jaoua, S. (2005). Overexpression of $\Delta 1$-pyrroline-5-carboxylate synthetase increases proline production and confers salt tolerance in transgenic potato plants. Plant Sci. 169, 746-752. doi: 10.1016/j.plantsci.2005. 05.025 
Horie, T., Hauser, F., and Schroeder, J. I. (2009). HKT transporter-mediated salinity resistance mechanisms in Arabidopsis and monocot crop plants. Trends Plant Sci. 14, 660-668. doi: 10.1016/j.tplants.2009.08.009

Huang, Z., Zhao, L., Chen, D., Liang, M., Liu, Z., Shao, H., et al. (2013). Salt stress encourages proline accumulation by regulating proline biosynthesis and degradation in Jerusalem Artichoke plantlets. PLOS ONE 8:e62085. doi: 10.1371/journal.pone.0062085

Jaarsma, R., de Vries, R. S. M., and de Boer, A. H. (2013). Effect of salt stress on growth, $\mathrm{Na}^{+}$accumulation and proline metabolism in potato (Solanum tuberosum) cultivars. PLOS ONE 8:e60183. doi: 10.1371/journal.pone.00 60183

Ji, H., Pardo, J. M., Batelli, G., Van Oosten, M. J., Bressan, R. A., and Li, X. (2013). The salt overly sensitive (SOS) pathway: established and emerging roles. Mol. Plant 6, 275-286. doi: 10.1093/mp/sst017

Kishor, P. B. K., Sangam, S., Amrutha, R. N., Laxmi, P. S., Naidu, K. R., Rao, K. R. S. S., et al. (2005). Regulation of proline biosynthesis, degradation, uptake and transport in higher plants: its implications in plant growth and abiotic stress tolerance. Curr. Sci. 88, 424-438.

Kishore, B., Hong, Z., Miao, G., Hu, C., and Verma, D. (1995). Overexpression of delta-pyrroline-5-carboxylatesynthetase increase proline production and confers osmotolerance in transgenic plants. Plant Physiol. 108, 1387-1394.

Lu, Y., Li, N., Sun, J., Hou, P., Jing, X., Zhu, H., et al. (2013). Exogenous hydrogen peroxide, nitric oxide and calcium mediate root ion fluxes in two nonsecretor mangrove species subjected to $\mathrm{NaCl}$ stress. Tree Physiol. 33, 81-95. doi: 10.1093/treephys/tps119

Lutts, S., Majerus, V., and Kinet, J. M. (1999). NaCl effects on proline metabolism in rice (Oryza sativa L.) seedlings. Physiol. Plant. 105, 450-458. doi: 10.1034/j.1399-3054.1999.105309.x

Maas, E. V., and Hoffman, G. J. (1977). Crop salt tolerance, current assessment. ASCE J. Irrig. Drain. Div. 103, 115-134.

Maathuis, F. J. M. (2014). Sodium in plants: perception, signalling, and regulation of sodium fluxes. J. Exp. Bot. 65, 849-858. doi: 10.1093/jxb/ert326

Malagoli, P., Britto, D. T., Schulze, L. M., and Kronzucker, H. J. (2008). Futile $\mathrm{Na}^{+}$ cycling at the root plasma membrane in rice (Oryza sativa L.): kinetics, energetic, and relationship to salinity tolerance. J. Exp. Bot. 59, 4109-4117. doi: $10.1093 /$ jxb/ern249

Mimura, T., Kura-Hotta, M., Tsujimura, T., Ohnishi, M., Miura, M., Okazaki, Y., et al. (2003). Rapid increase of vacuolar volumen in response to salt stress. Planta 216, 397-402. doi: 10.1007/s00425-002-0878-2

Moftah, A. E., and Michel, B. E. (1987). The effect of sodium chloride on solute potential and proline accumulation in soybean leaves. Plant Physiol. 83, 238-240. doi: 10.1104/pp.83.2.238

Moscone, E. A., Scaldaferro, M. A., Grabiele, M., Cecchini, N. M., Sánchez-García, Y., Jarret, R., et al. (2007). The evolution of chili peppers (Capsicum-Solanaceae): a cytogenetic perspective. Acta Hortic. 745, 137-170. Available online at: http:// www.actahort.org/books/745/745_5.htm

Munns, R., and Tester, M. (2008). Mechanisms of salinity tolerance. Annu. Rev. Plant Biol. 59, 651-681. doi: 10.1146/annurev.arplant.59.032607. 092911

Newman, I. A. (2001). Ion transport in roots: measurement of fluxes using ion-selective microelectrodes to characterize transporter function. Plant Cell Environ. 24, 1-14. doi: 10.1046/j.1365-3040.2001.00661.x

Oh, D.-H., Leidi, E., Zhang, Q., Hwang, S.-M., Li, Y., Quintero, F. J., et al. (2009). Loss of halophytism by interference with SOS1 expression. Plant Physiol. 151, 210-222. doi: 10.1104/pp.109.137802

Palmgren, M., and Nissen, P. (2010). P-type ATPases. Annu. Rev. Biophys. 40, 243-266. doi: 10.1146/annurev.biophys.093008.131331

Pasapula, V., Shen, G., Kuppu, S., Paez-Valencia, J., Mendoza, M., Hou, P., et al. (2011). Expression of an Arabidopsis vacuolar H+-pyrophosphatase gene $(A V P 1)$ in cotton improves drought and salt tolerance and increase fibre yield in the field conditions. Plant Biotechnol. J. 9, 88-99. doi: 10.1111/j.14677652.2010.00535.x

Perry, L., Dickau, R., Zarrillo, S., Holst, I., Pearsall, D. M., Piperno, D. R., et al. (2007). Starch fossils and the domestication and dispersal of chili peppers (Capsicum spp. L.) in the Americas. Science 325, 986-988. doi: 10.1126/science. 1136914

Pittman, J. K. (2012). Multiple transport pathways for medianting intracellular $\mathrm{pH}$ homeostasis: the contribution of $\mathrm{H}+/$ ion exchangers. Front. Plant Sci. 3:11. doi: 10.3389/fpls.2012.00011
Plett, D. C., and Moller, I. S. (2010). $\mathrm{Na}^{+}$transport in glycophytic plants: what we know and would like to know. Plant Cell Environ. 33, 612-626. doi: 10.1111/j.1365-3040.2009.02086.x

Qin, C., Yu, C., Shen, Y., Fang, X., Chen, L., Min, J., et al. (2014). Whole-genome sequencing of cultivated and wild peppers provides insights into Capsicum domestication and specialization. Proc. Natl. Acad. Sci. U.S.A. 111, 5135-5140. doi: 10.1073/pnas.1400975111

Queirós, F., Fontes, N., Silva, P., Almeida, D., Maeshima, M., Gerós, H., et al. (2009). Activity of tonoplast proton pumps and $\mathrm{Na}^{+} / \mathrm{H}^{+}$exchange in potato cell cultures is modulated by salt. J. Exp. Bot. 60, 1363-1374. doi: 10.1093/jxb/ erp011

Ramani, B., Reeck, T., Debez, A., Stelzer, R., Huchzermeyer, B., Schmidt, A., et al. (2006). Aster tripolium L. and Sesuvium portulacastrum L.: two halophytes, two strategies to survive in saline habitats. Plant Physiol. Biochem. 44, 395-408. doi: 10.1016/j.plaphy.2006.06.007

Rodríguez-Rosales, M. P., Gálvez, F. J., Huertas, R., Aranda, M. N., Baghour, M., Cagnac, O., et al. (2009). Plant NHX catión/proton antiporters. Plant Signal. Behav. 4, 265-276. doi: 10.4161/psb.4.4.7919

Rodríguez-Rosales, M. P., Jiang, X., Gálvez, F. J., Aranda, M. N., Cubero, B., and Venema, K. (2008). Overexpression of the tomato $\mathrm{K}^{+} / \mathrm{H}^{+}$antiporter LeNHX2 confers salt tolerance by improving potassium compartmentalization. New Phytol. 179, 366-377. doi: 10.1111/j.1469-8137.2008. 02461.x

Roy, S. J., Negrão, S., and Tester, M. (2014). Salt resistant crop plants. Curr. Opin. Biotechnol. 26, 115-124. doi: 10.1016/j.copbio.2013.12.004

Ruan, C.-J., Teixeira da Silva, J. A., Mopper, S., Qin, P., and Lutts, S. (2010). Halophyte improvement for a salinized world. CRC. Crit. Rev. Plant Sci. 29, 329-359. doi: 10.1080/07352689.2010.524517

Rubio, F., Flores, P., Navarro, J. M., and Martínez, V. (2003). Effects of $\mathrm{Ca}^{2+}, \mathrm{K}^{+}$ and cGMP on $\mathrm{Na}^{+}$uptake in pepper plants. Plant Sci. 165, 1043-1049. doi: 10.1016/S0168-9452(03)00297-8

Shabala, S. (2013). Learning from halophytes: physiological basis and strategies to improve abiotic stress tolerance in crops. Ann. Bot. 112, 1209-1221. doi: 10.1093/aob/mct205

Shabala, S., and Cuin, T. A. (2007). Potassium transport and plant salt tolerance. Physiol. Plant. 133, 651-669. doi: 10.1111/j.1399-3054.2007.01008.x

Shabala, S., Demidchik, V., Shabala, L., Cuin, T. A., Smith, S. J., Miller, A. J., et al. (2006). Extracellular $\mathrm{Ca}^{2+}$ ameriorates $\mathrm{NaCl}$-induced $\mathrm{K}^{+}$loss from Arabidopsis root and leaf cells by controlling plasma membrane $\mathrm{K}^{+}$permeable channels. Plant Physiol. 141, 1653-1665. doi: 10.1104/pp.106. 082388

Shabala, S., and Pottosin, I. (2014). Regulation of potassium transport in plants under hostile conditions: implications for abiotic and biotic stress tolerance. Physiol. Plant. 151, 257-279. doi: 10.1111/ppl.12165

Shabala, S., and Shabala, L. (2011). Ion transport and osmotic adjustment in plants and bacteria. Biomol. Concepts 2, 407-419. doi: 10.1515/BMC.20 11.032

Sharma, S., Villamor, J. G., and Verslues, P. E. (2011). Essential role of tissue-specific proline synthesis and catabolism in growth and redox balance at low water potential. Plant Physiol. 157, 292-304. doi: 10.1104/pp.111.183210

Shen, G., Wei, J., Qiu, X., Hu, R., Kuppu, S., Auld, D., et al. (2014). Cooverexpression of AVP1 and AtNHX1 in cotton further improves drought and salt tolerance in transgenic cotton plants. Plant Mol. Biol. Rep. doi: 10.1007/s11105-014-0739-8. [Epub ahead of print].

Shi, H., Quintero, F. J., Pardo, J. M., and Zhu, J.-K. (2002). The putative plasma membrane $\mathrm{Na}^{+} / \mathrm{H}^{+}$antiporter SOS1 controls long-distance $\mathrm{Na}+$ transport in plants. Plant Cell 14, 465-477. doi: 10.1105/tpc.010371

Smethurst, C. F., Rix, K., Garnett, T., Auricht, G., Bayart, A., Lane, P., et al. (2008). Multiple traits associated with salt tolerance in lucerne: revealing the underlying cellular mechanisms. Funct. Plant Biol. 35, 640-650. doi: 10.1071/FP 08030

Sun, J., Dai, S., Wang, R., Chen, S., Li, N., Zhou, X., et al. (2009). Calcium mediates root $\mathrm{K}^{+} / \mathrm{Na}^{+}$homeostasis in poplar species differing in salt tolerance. Tree Physiol. 29, 1175-1186. doi: 10.1093/treephys/tpp048

Szabados, L., and Savouré, A. (2009). Proline: a multifunctional amino acid. Trends Plant Sci. 15, 89-97. doi: 10.1016/j.tplants.2009.11.009

Verslues, P. E., and Sharma, S. (2010). Proline metabolism and its implications for plant-environmental interaction. Arabidopsis Book 8:e0140. doi: 10.1199/ tab.0140 
Volkov, V., and Amtmann, A. (2006). Thellungiella halophila, a salt-tolerant relative of Arabidopsis thaliana, has specific root ion-channel features supporting $\mathrm{K}^{+} / \mathrm{Na}^{+}$homeostasis under salinity stress. Plant J. 48, 342-353. doi: 10.1111/j.1365-313X.2006.02876.x

Wu, H., Shabala, L., Barry, K., Zhou, M., and Shabala, S. (2013). Ability of leaf mesophyll to retain potassium correlates with salinity tolerance in wheat and barley. Physiol. Plant. 149, 515-527. doi: 10.1111/ppl.12056

Yildiztugay, E., Sekmen, A. H., Turkan, I., and Kucukoduk, M. (2011). Elucidation of physiological and biochemical mechanisms of an endemic halophyte Centaurea tuzgoluensis under salt stress. Plant Physiol. Biochem. 49, 816-824. doi: 10.1016/j.plaphy.2011.01.021

Zepeda-Jazo, I., Shabala, S., Chen, Z., and Pottosin, I. I. (2008). $\mathrm{Na}^{+}-\mathrm{K}^{+}$ transport in roots under salt stress. Plant Signal. Behav. 3, 401-403. doi: $10.4161 /$ psb.3.6.5429

Zhang, J.-L., and Shi, H. (2013). Physiological and molecular mechanisms of plant salt tolerance. Photosyn. Res. 115, 1-22. doi: 10.1007/s11120-0139813-6

Zhao, F., Song, C. P., He, J., and Zhu, H. (2007). Polyamines improve $\mathrm{K}^{+} / \mathrm{Na}^{+}$ homeostasis in barley seedlings by regulating root ion channel activities. Plant Physiol. 145, 1061-1072. doi: 10.1104/pp.107.105882
Conflict of Interest Statement: The authors declare that the research was conducted in the absence of any commercial or financial relationships that could be construed as a potential conflict of interest.

Received: 13 August 2014; accepted: 17 October 2014; published online: 12 November 2014.

Citation: Bojórquez-Quintal E, Velarde-Buendía A, Ku-González Á, Carillo-Pech M, Ortega-Camacho D, Echevarría-Machado I, Pottosin I and Martínez-Estévez M (2014) Mechanisms of salt tolerance in habanero pepper plants (Capsicum chinense Jacq.): Proline accumulation, ions dynamics and sodium root-shoot partition and compartmentation. Front. Plant Sci. 5:605. doi: 10.3389/fpls.2014.00605

This article was submitted to Crop Science and Horticulture, a section of the journal Frontiers in Plant Science.

Copyright (c) 2014 Bojórquez-Quintal, Velarde-Buendía, Ku-González, Carillo-Pech, Ortega-Camacho, Echevarría-Machado, Pottosin and Martinez-Estévez. This is an open-access article distributed under the terms of the Creative Commons Attribution License (CC BY). The use, distribution or reproduction in other forums is permitted, provided the original author(s) or licensor are credited and that the original publication in this journal is cited, in accordance with accepted academic practice. No use, distribution or reproduction is permitted which does not comply with these terms. 